\title{
LAS LEYES DE ACOMPAÑAMIENTO Y EL PROBLEMA DE LAS «LEYES ÓMNIBUS"
}

\author{
ISABEL M. GIMÉNEZ SÁNCHEZ \\ Profesora de Derecho Constitucional \\ Universidad Autónoma de Madrid
}

SUMARIO

I. Breve historia de las llamadas "Leyes de acompañamiento"

II. El fenómeno de las "Leyes ómnibus" en el Derecho comparado

III. El problema de las "Leyes ómnibus" en el ordenamiento constitucional español

IV. Conclusiones y alternativas posibles

\section{BREVE HISTORIA DE LAS LLAMADAS «LEYES DE ACOMPAÑAMIENTO"}

Pocas cuestiones han concitado la crítica unánime de la doctrina, de los aplicadores del Derecho y de las más diversas instituciones en un grado tal como el alcanzado por la práctica anual de la aprobación de la llamada Ley de Medidas Fiscales, Administrativas y de Orden Social (más conocida por todos como Ley de Acompañamiento de la Ley de Presupuestos Generales del Estado $)^{1}$. El dato más destacable, a los efectos del presente estudio, en rela-

1 Sin embargo, entre la doctrina llegó a hacer fortuna su denominación como Ley de Medidas (ver, por todos, A. Jiménez DíAz, "La impugnación de las Leyes Medidas como problema. Consideraciones desde la jurisprudencia constitucional sobre la Ley de Presupuestos", REDF, núm. 112, 2001, págs. 639-682) que, creemos, puede dar lugar a equívocos. Por el contrario, en un primer momento se empleó doctrinal e, incluso, parlamentariamente la denominación de "Ley Financiera", que tomaba el nombre influido del sistema italiano. Hoy, entre nosotros, ese es el nombre que recibe otra ley — también de grandes dimensiones y contenido no precisamente homogéneo- cuya finalidad es la de incorporar en una norma única todas las reformas de las diferentes leyes que regulan el sistema financiero. En efecto, la Ley Financiera es otro tipo de ley 
ción con esta nueva tipología legislativa fue, sin duda, el de su progresivo y constante incremento de contenido, reflejo de una marcada tendencia a acumular disposiciones legislativas, recogidas de manera aleatoria y asistemática en leyes ómnibus que debían promulgarse forzosamente al final del año. Se aprovechaba así, tanto la estela de la agilidad procedimental en la tramitación de las Leyes de Presupuestos Generales del Estado (en adelante, LPGE), como la práctica necesidad de su aprobación, sin verse afectadas, en cambio, por las restricciones que la Constitución y los Reglamentos de las Cámaras establecen respecto de aquéllas².

Que existió un vínculo directo entre la doctrina del Tribunal Constitucional sobre el contenido material de las Leyes de Presupuestos y el surgimiento de las Leyes de Acompañamiento es algo difícilmente cuestionable ${ }^{3}$. A este respecto, resulta ciertamente revelador el hecho de que la primera de estas Leyes de Acompañamiento - titulada entonces como Ley de Medidas Fiscales, de Reforma del Régimen Jurídico de la Función Pública y de la Protección por Desempleo (Ley 22/1993, de 29 de diciembre), fuese aprobada precisamente en el ejercicio sucesivo al de la decisiva STC 76/1992, esto es, aquel pronunciamiento en el que el Tribunal había acotado de manera inequívoca el ámbito material de las Leyes de Presupuestos. Pese a que en la Exposición de Motivos de esta primera Ley de Acompañamiento sólo se reconocía como motivación de la misma las necesidades económicas coyunturales ${ }^{4}$, lo cierto es que pasaron a incluirse en ella todas esas "normas adosadas" — cuya presencia hasta entonces se había concentrado en las LPGE. Es obvio, sin em-

"escoba", pero que en este caso modifica el conjunto de leyes que regulan el mercado de valores, las entidades de crédito, las sociedades de capital riesgo, e incluso instituciones como el Banco de España y la CNMV.

2 Como sarcásticamente se lamentaba Santamaría Pastor, estas leyes acabaron por convertirse en "un horror más que añadir a los trastornos gástricos producidos por un período festivo inacabable" ["El sistema de fuentes del Derecho en los primeros cincuenta años de vida de la Revista de Administración Pública (1950-1999)", RAP, núm. 150, 1999, págs. 550 y sigs.]

3 Doctrina ésta que se encuentra perfectamente sintetizada, en palabras del propio Tribunal, en la STC 174/1998, de 23 de julio (FJ 6º : "Como viene insistiendo este Tribunal (por todas, SSTC 76/1992 y 195/1994) dos son los requisitos necesarios para que la regulación por Ley de Presupuestos de una materia que no forma parte de su contenido necesario sea constitucionalmente legítima: de una parte, es preciso que la materia guarde relación directa con los ingresos y gastos que integran el Presupuesto y que su inclusión esté justificada por ser un complemento de los criterios de política económica de la que ese Presupuesto es el instrumento; y de otra, que "sea un complemento necesario para la mayor inteligencia y para la mejor ejecución del Presupuesto y, en general, de la política económica del Gobierno" (SSTC 76/1992 y 195/1994)."

4 Concretamente, se hablaba de "la adopción de medidas legislativas de diversa índole que coadyuven al cabal cumplimiento de los objetivos económicos previstos en la Ley de Presupuestos Generales del Estado para 1994". Pese a ello, poco tiempo después, en el propio Preámbulo de la LPGE para 1994, ya se hacía referencia de manera directa y expresa — si bien sólo respecto de las medidas fiscales- a la doctrina del Tribunal como causa esencial de este "desdoblamiento legislativo forzado".

5 Según la terminología empleada por A. RodríguEz BEREIJo, en su obra "Sobre técnica jurídica y Leyes de Presupuestos", incluida en el Homenaje a C. Albiñana, vol. I., EDH, Madrid, 1987, pág. 657. 
bargo, que el surgimiento de estas leyes respondía a otro tipo de motivaciones más profundas, precisamente aquéllas que habían venido determinando la inclusión de ciertas normas en las Leyes de Presupuestos antes de que las mismas viesen reducido su contenido a través de la labor interpretativa desarrollada por el Tribunal Constitucional. Entre dichas causas destaca, en primer lugar, la extrema variabilidad de la realidad política, especialmente acentuada en el campo de la economía, a la que debe hacerse frente de manera constante y con la mayor celeridad posible. Por otro lado, no podemos olvidar la existencia de razones de conveniencia política de los Gobiernos en la utilización de un vehículo normativo como éste que nos ocupa, que presenta la innegable ventaja de contar con unos plazos ciertos y preestablecidos de aprobación. Asimismo, y como consecuencia de lo anterior, las leyes ómnibus - cualesquiera que éstas sean- posibilitan la inclusión de materias varias, sin dar lugar a eternos debates y discusiones parlamentarias, permitiendo así un mayor control del Ejecutivo sobre su propio proyecto a lo largo de toda la tramitación en las Cámaras. Rasgo este último que cobra una importancia decisiva en aquellos supuestos en que el Ejecutivo no cuenta con el respaldo de una mayoría absoluta en el Parlamento.

Partiendo de estos sucintos rasgos explicativos que, por otra parte, a nadie escapan, es de destacar, asimismo, la evolución paulatina sufrida tanto en el contenido como en la filosofía subyacentes a este tipo legislativo a lo largo de su corta vida. Nos referimos, ante todo, al progresivo incremento de disposiciones incluidas anualmente en las Leyes de Acompañamiento, que parecía responder a un cambio esencial en la comprensión de la naturaleza de estas leyes. Así, se pasa de un momento inicial — que abarcaría sus dos primeros años de existencia (ejercicios de 1994 y 1995) — en el que las Leyes de Acompañamiento venían concebidas como un mero complemento de las Leyes anuales de Presupuestos, incluyendo sólo aquellas materias que no tenían cabida en estas últimas, después de la restricción operada por la doctrina del Tribunal Constitucional. Posteriormente, sin embargo, se pasó a otra fase en la que estas leyes no se limitaban a complementar las LPGE, sino que claramente perseguían los más variados objetivos de política económica ${ }^{6}$. De este modo, las Leyes de Acompañamiento se convirtieron en uno de los principales instrumentos de que disponía el Gobierno para diseñar su política eco-

6 En este caso las cifras son especialmente ilustrativas y nos eximen de mayores aclaraciones al respecto. La primera Ley de Acompañamiento (la 21/1993 de 29 de diciembre, a la que nos hemos referido ya), se dividía en tres títulos y contenía 43 artículos, 19 Disposiciones Adicionales, 4 Transitorias, 1 Derogatoria y 2 Disposiciones Finales; modificándose con ella 13 leyes, 2 decretos legislativos y 1 decreto ley. Tan sólo cinco años después, la Ley 50/1998, de 30 de diciembre, consta ya de 11 artículos, 44 Disposiciones Adicionales, 17 Transitorias, 7 Derogatorias y 6 Disposiciones Finales, sistematizados en cinco títulos. Pero lo más destacable es, sin duda, la cantidad de disposiciones con rango de ley afectadas por ella: 76 leyes, 7 decretos legislativos y 6 decretos-leyes [Los datos están tomados de la intervención del profesor Ramallo Massanet, con el título "El bloque presupuestario en España: Presupuestos, Acompañamiento y Estabilidad", dentro del Seminario El Presupuesto en el Parlamento, celebrado en la Fundación Pablo Iglesias los días 24 y 25 de Septiembre de 2002] 
nómica. En definitiva, con este cambio en su propia fundamentación, se vino a admitir «un contenido prácticamente universal de las llamadas Leyes de Acompañamiento presupuestario" ${ }^{7}$. De esta suerte, en los últimos ejercicios, las Leyes de Acompañamiento superaban ya los 10 artículos y contenían más de cien disposiciones, entre adicionales, transitorias, finales y derogatorias, lo que requería de unos cinco títulos para agruparlas ${ }^{8}$. Pero, aún más grave, es el hecho de que una media de ochenta disposiciones con rango de ley acababan siendo modificadas anualmente a través de estas leyes, abarcando las temáticas más dispares: subvenciones electorales, deporte, televisiones privadas, maltrato doméstico, tasas judiciales, marco tarifario para el sector eléctrico, así como las ya clásicas disposiciones en materia de función pública, regulación de las cajas de ahorros, la modificación del Plan Hidrológico Nacional o, incluso, la Ley de Tráfico. De hecho, se aprobaban, reformaban o derogaban más normas por medio de las Leyes de Medidas Fiscales, Administrativas y del Orden Social anuales, que por medio del resto de la actividad legislativa ordinaria de las Cámaras. Y así hasta llegar a la última de ellas, la Ley 62/2003, que llegó a modificar 113 leyes de contenido tan distinto como la Ley de Enjuiciamiento Civil, el Código de Comercio, la Ley Hipotecaria, la General de Sanidad, la de la Energía Nuclear, la de Televisión Privada, la del Mercado de Valores, la del Medicamento, la del Sector Eléctrico, la General de Telecomunicaciones, la de Protección de Datos de Carácter Personal, la reguladora del Centro Nacional de Inteligencia, o la del Plan Hidrológico Nacional, entre otras muchas.

En septiembre de 2004, tras las elecciones, el nuevo Gobierno -en cumplimiento del compromiso electoral del PSOE de devolver al Parlamento su protagonismo, facilitar el control por parte de éste de las cuentas del Estado e impulsar el rigor político-, anunciaba que no habría Ley de Acompañamiento a los Presupuestos Generales del Estado de 2005․ De esta manera, el Gobierno informó de que las reformas legislativas requeridas desde el Gobierno serían presentadas "una por una" a través de su trámite correspondiente, permitiendo su estudio "riguroso" a las diferentes comisiones parlamentarias. Sin embargo, lo cierto es que la LPGE para 2005 incluyó unos 48 preceptos que modificaban una decena de leyes (la Ley General de Estabilidad Presupuestaria, entre otras), afectando a políticas sectoriales ajenas a la materia presupuestaria, además de crear un nuevo tributo, excediendo así del ámbito de la propia LPGE. En definitiva, esta medida, saludada con entusiasmo desde la doctrina ${ }^{10}$, fue observada con recelo desde la oposición, por en-

7 L. M. Cazorla Prieto, Las llamadas Leyes de Acompañamiento presupuestario. Sus problemas de constitucionalidad, Instituto de Estudios Fiscales, Marcial Pons, Madrid, 1998, págs. 43-44.

8 L. Jimena Quesada, Dirección política del Gobierno y técnica legislativa, Tecnos, Madrid, 2003, págs. 217 y sigs.

9 En efecto, la situación fue comparada irónicamente con la "criatura de Frankenstein" finalmente eliminada por su propio creador, en este caso el Vicepresidente económico, Sr. Solbes.

10 Con la salvedad del Instituto de Estudios Económicos (IEE) que consideraba que la supresión de la Ley de Acompañamiento a los presupuestos, restaría agilidad al Gobierno para 
tender que las Leyes de Presupuestos volvían a asumir contenidos excesivos, rechazados en su día por la doctrina del Tribunal Constitucional ${ }^{11}$. Por otro lado, un año después, a tan sólo unos meses de la aprobación de la LPGE para 2006, se publicaba la Ley 24/2005, de 18 de noviembre, de reformas para el impulso a la productividad. Esta ley ómnibus, bajo la pretensión de introducir reformas de carácter liberalizador en los mercados de bienes y servicios y mejorar el funcionamiento de la Administración en sus relaciones con los ciudadanos, venía en la práctica a suplir la ausencia de la habitual Ley de Acompañamiento ${ }^{12}$.

Vemos, por tanto, que a pesar de la desaparición formal de las Leyes de Acompañamiento, el problema de fondo no ha desaparecido del todo ${ }^{13}$. A lo sumo se ha transformado. En primer lugar, porque estas leyes han sido suprimidas en el ordenamiento jurídico estatal, mientras que el fenómeno continúa en su máximo apogeo en la gran mayoría de los ordenamientos autonómicos, dando lugar a conflictos como los ya expuestos en relación con las Leyes de Acompañamiento a los $\mathrm{PGE}^{14}$. En segundo lugar, porque periódicamente surgen voces - más o menos acreditadas - que abogan por la resurrección de este tipo legislativo. Y por último — aunque a mi juicio éste es el

adoptar reformas estructurales, al tiempo que defendía que se trataba de un cambio "más cosmético que real", dada la introducción de numerosas disposiciones adicionales en la LPGE que también regulan cuestiones "variopintas" (Datos derivados de su estudio sobre los Presupuestos Generales del Estado para 2005).

11 De hecho, el Grupo Popular presentó un recurso de inconstitucionalidad contra los Presupuestos de 2005 por este motivo. Entre los preceptos considerados inconstitucionales, se hallaba la disposición 48 LPGE, que modifica la Ley del Medicamento creando una exacción para financiar parte del programa de fomento de la investigación, por vulnerar la prohibición del art. 134.7 CE. Asimismo, el Grupo Popular denunciaba aquellas otras medidas incluidas en el proyecto de ley que son de ámbito sectorial y que "poco tienen que ver con la materia presupuestaria", como las que modifican la Ley del Catastro Inmobiliario, o el régimen de devengo de retribuciones de los funcionarios públicos, o la que privatiza la gestión del Sistema Nacional de Compensación Electrónica.

12 De acuerdo con esta Ley — en la que sólo faltaban las medidas del orden social—, entre otras materias, hacía desaparecer la tarifa de suministro de electricidad en alta tensión en 2010 , habilitaba al Gobierno para actualizar el régimen retributivo de la Comisión Nacional de Energía, se permitía la combustión de biomasa en las instalaciones del régimen ordinario, se permitía a las cooperativas agrícolas comercializar carburantes, se habilitaba a la Comisión Nacional de Energía para resolver las liquidaciones de gas, se dotaba de vinculatoriedad a las Instrucciones del Consejo de Seguridad Nuclear, se establecía la obligación universal de prevención del tráfico ilegal de materiales nucleares, se implantaba un mecanismo de mercado para valorar los emplazamientos de las centrales nucleares en moratoria y se reformaba la regulación del sistema de distribución del mercado de tabacos.

13 También de acuerdo con la persistencia del problema, pese a la anunciada desaparición de las Leyes de Acompañamiento, se manifiesta S. Moreno GonzÁlez, "De nuevo sobre el contenido constitucionalmente admisible de la Ley de Presupuestos Generales del Estado: ¿Una vuelta a los orígenes?", Revista Información Fiscal, septiembre-octubre 2005, pág. 12.

14 J. Calvo Vérgez, "Algunas consideraciones sobre el principio de reserva de ley en materia presupuestaria: Especial referencia a la restricción ocasionada por el contenido adicional de las leyes de presupuestos estatales y por las leyes de medidas autonómicas", Crónica Tributaria, núm. 14, 2005, págs. 70 y sigs. 
rasgo más destacado- porque, como acabo de señalar, el fenómeno de las leyes ómnibus (esto es, de cajones de sastre recolectores de un sinfín de materias legales a reformar) parece ser una maldición casi ineludible, que acaba resurgiendo con esta o aquella forma, con uno u otro nombre. La cuestión aquí ya no será, por tanto, la de la constitucionalidad de una ley desdoblada de la de Presupuestos Generales del Estado (y por tanto fraudulentamente superadora de los límites constitucionalmente impuestos a la LPGE), sino de la admisibilidad de las "leyes escobas".

En ese sentido, el problema básico que se planteó en la década de los 80 del pasado siglo respecto de las LPGE, cuando se hablaba de "leyes ómnibus", "avalancha normativa" y "alarma social", siguió manifestándose con la misma gravedad, si no mayor, respecto de las polémicas Leyes de Acompañamiento $^{15}$. Ello condujo a la inmensa mayoría de la doctrina a considerar que estas Leyes representaban la "fórmula propiciatoria para burlar el contenido predeterminado constitucionalmente de las Leyes de Presupuestos Generales del Estado" ${ }^{16}$. Sin embargo, la utilización del expediente de las Leyes de Acompañamiento para eludir las limitaciones constitucionalmente impuestas a las Leyes de Presupuestos no es algo consustancial al ordenamiento español. De hecho, muchos han cifrado su origen - más o menos directo- en el sistema italiano, donde a finales de los años 70 surgió la figura de la Ley Financiera (legge finanziaria), cuyo fundamento se encuentra justamente en la idea de crear una figura normativa que superase las limitaciones de contenido que la Constitución italiana establece respecto de la Ley de Presupuestos (legge di bilancio). Por ello, hemos considerado de utilidad conocer cómo se ha hecho frente en los sistemas de nuestro entorno a esta tentación de los Ejecutivos de aprobar, junto a la Ley de Presupuestos anual, y aprovechando los procedimientos acelerados de la mismas, otras leyes caracterizadas por contener un sinfín de disposiciones heterogéneas, relativas a las materias más dispares. Con esta finalidad hemos optado por estudiar, de una parte, el sistema italiano, como referente más inmediato del caso español; y, de otra, los casos americano y francés, como ejemplos representativos de tendencias opuestas en cuanto al uso (y abuso) de estas figuras normativas ${ }^{17}$.

15 En esta misma línea, es claro que puede predicarse de las Leyes de Acompañamiento lo que previamente se había reprochado a las leyes de presupuestos por Martínez Val, a las que calificaba de "desastroso cajón de sastre, donde cada Ministro puede meter con facilidad cuanto no ha podido conseguir por medio de la legislación ordinaria o esa "Ley sorpresa" de donde puede salir todo..." ["Requisitos para legislar desde la Ley de Presupuestos (Comentarios a la sentencia del Tribunal Constitucional 76/1992, de 14 de mayo, BOE del 16 de junio)", Revista General del Derecho, núms. 577-578, 1994, pág. 9652].

16 M. A. Martínez Lago, "Leyes de Presupuestos y leyes "de acompañamiento": Aspectos constitucionales de los Presupuestos Generales del Estado y abuso de las formas jurídicas por el Gobierno)", REDF, núm. 104, 1999, pág. 785.

17 No obstante, también en Alemania se constata esta práctica de añadir leyes vinculadas al procedimiento presupuestario que, en este caso, presentan fundamentalmente dos variantes, las Leyes de Aseguramiento del Presupuesto (Haushaltssicherungsgeseztzen) y las Leyes de Acompañamiento del Presupuesto, propiamente dichas (Haushaltsbegleitgesetzsen). En ellas se pro- 


\section{EL FENÓMENO DE LAS «LEYES ÓMNIBUS»EN EL DERECHO COMPARADO}

Así pues, seguidamente analizaremos algunos de los fenómenos más característicos, prestando especial atención a los factores que condujeron a la creación de estas nuevas fuentes normativas, demostrando cómo se cumple inexorablemente la máxima latina del nibil sub sole novi. En todos estos casos nos encontramos ante leyes extraordinariamente largas, caracterizadas por la disparidad de disposiciones en ellas contenidas, sin relación material entre las mismas y aprobadas siguiendo la estela de las leyes de presupuestos, por lo que - en el mejor de los casos- se verán afectadas por la premura de los plazos de aprobación que a aquéllas incumbe.

\section{A) LA LEgGE FINANZIARIA ITALIANA}

En el contexto italiano, resulta innegable que, tras la introducción de este nuevo tipo de ley, subyace la convicción de que el art. 81 de la Constitución italiana configura la ley de presupuestos como una ley puramente formal, es decir, "totalmente vinculada y meramente reconocedora de los resultados contables de decisiones efectuadas en otro lugar y en otro momento" ${ }^{18}$. Un entendimiento éste que conlleva, como consecuencia, la imposibilidad de emplear la ley de presupuestos como instrumento de política económica del Gobierno $^{19}$. De hecho, la doctrina italiana ha utilizado la idea de la "conexión

ponen modificaciones sustantivas urgentes al contenido de leyes de asignación de los gastos autorizados del Estado federal. Así, mediante la aprobación de estas leyes, "con ocasión de la presentación del Presupuesto y de la aprobación de la Ley de Presupuestos se emprenden esfuerzos periódicos para recortar las necesidades del Estado o al menos clasificarlas de manera ordenada y planificada desde el punto de vista económico-financiero". Básicamente, esta práctica implica que, con ocasión de la aprobación de la Ley de Presupuestos mediante una Ley articulada resulta modificada una serie de leyes de asignación de gasto, para superar las necesidades financieras de conformidad con las obligaciones legales que deban cubrirse desde el Presupuesto público [Vid. P. BADURA, Staatsrecht: Systematische Erläuterung des Grundgesetzes für die Bundesrepublik Deutschland, 2a ed., C. H. Beck, Munich, 1996, págs. 645-6].

18 Si bien literalmente el texto del art. 81.3 de la Constitución sólo establece que "[c]on la ley de aprobación del presupuesto no se pueden establecer nuevos tributos y nuevos gastos", fue la propia Corte Constitucional (en su sentencia de 2 de marzo de 1959, núm. 7) quien concibió la Ley de Presupuestos como una ley formal de autorización, al sostener que «es una ley formal que no puede contener ninguna innovación legislativa, de modo que de ella no puedan derivarse ni compromisos, ni derechos distintos de aquellos preexistentes a la propia ley".

19 Pese a que la concepción de la legge di bilancio como ley formal ha sido siempre evidente en la jurisprudencia de la Corte, impidiéndole tajantemente la realización de cualquier innovación en el ordenamiento, la elaboración de la propia idea de la legge finanziaria tiene su origen en la doctrina científica, a principios de la década de los setenta [concretamente en un artículo de A. Amatucci (Funzioni e disciplina del bilancio dello Stato, Jovene, Nápoles, 1970, pág. 175), que es el primero en darle forma jurídica, aunque ya en 1967 Buscema había sugerido algo parecido] y su recepción en el Derecho positivo no tuvo lugar hasta 1978, cuando la ley de 5 de agosto, núm. 468, en su art. 11, vino a establecer por vez primera la figura de la Ley Financiera. 
funcional" para explicar la relación existente entre la Ley de Presupuestos (legge di bilancio) y la Ley Financiera (legge finanziaria) ${ }^{20}$. Teniendo en cuenta que la principal finalidad de este nuevo tipo legislativo era la de "proporcionar cobertura legal, en los términos de la Constitución italiana, a todos los gastos así como a la cuota correspondiente a los gastos plurianuales que es necesario consignar en el Presupuesto anual y a los recursos —en especial el recurso del endeudamiento público— de que se dispone para hacerlos frente.... ${ }^{21}$, se comprueba claramente que a la Ley Financiera le estaba permitido aquello que la Constitución prohíbe a la Ley de Presupuestos, esto es, modificar leyes con efecto presupuestario, tanto respecto de los ingresos como de los gastos. Esto hizo que, en sí misma considerada, resultase una figura problemática, a medio camino entre la legislación material de gasto y la Ley de Presupuestos, pero privada de un preciso respaldo constitucional en la jerarquía de fuentes $^{22}$. Dicha ambigüedad planteaba contradicciones ya desde su origen (dando lugar casi a un dilema respecto de su consideración financiera) ${ }^{23}$, por lo que fueron varias las voces en la doctrina que no dudaron en calificar de inconstitucional esta figura diseñada por la ley 468/1978, acusándola de eludir la prohibición del apartado $3^{\circ}$ del art. 81, hasta el punto de que incluso el informe del Tribunal de Cuentas al Parlamento italiano sobre la Ley de Cuentas para 1978, llegó a calificarlo de revisión subrepticia del art. 81 de la Constitución.

20 En efecto, el propio Amatucci ha sostenido que «esta concreta ley está ligada a la ratio de la ley de presupuestos, puesto que es emanada en función del ejercicio de un determinado indirizzo politico económico; se trata, por tanto, de una relación de interdependencia que fluye entre la ratio de dicha ley y la de ley de presupuestos". Además, añade que dicha "conexión funcional entre la ley de presupuestos y la ley "financiera" resulta muy semejante a la existente en el derecho privado entre algunos negocios jurídicos, que son definidos precisamente como "coneXoS"m. A. AmatUCCI, "Il ruolo politico della legge finanziaria", en Studi in onore di Luigi Galateria, Maggioli, Rímini, 1987, pág. 52. pág. 787

21 M. A. Martínez Lago, "Leyes de Presupuestos y "Leyes de Acompañamiento"...", cit.,

22 Además del hecho de que si se trata de una ley cuya finalidad es su propia conexión con la Ley de Presupuestos, la existencia de un contenido eventual (junto al necesario, que siempre vendría legalmente definido) de la misma resulta difícilmente explicable desde una perspectiva jurídica [Vid. A. Brancasi, Legge Finanziaria e Legge di Bilancio, Giuffrè, Milán, 1985, págs. 12 y sigs.]

23 En el sentido de que si la legge finanziaria se empleaba para la adopción de decisiones no comprendidas en el ámbito de la política presupuestaria, se estaría violando materialmente el art. 81 de la Constitución (en sus apartados 3 y 4), pero si, por el contrario, esta ley se mantenía «en unos límites admisibles, coherentes con la función económica que el legislador pretendía asignarle, entonces ésta puede y debe reconducirse dentro del marco de las previsiones del art. 81 de la Constitución y, por tanto, en el ámbito de un único instrumento legislativo presupuestarion. Por eso mismo, algunos autores partidarios de una concepción material de la Ley de Presupuestos, defienden no una modificación del art. 81 de la Constitución, sino una correcta interpretación del mismo, que conduciría a la necesaria simplificación de los procedimientos y los instrumentos legislativos en materia presupuestaria [D. MARRA, "Legge finanziaria e legge di bilancio", en Strumenti per il controllo della spesa pubblica, Istituto Poligrafico e Zecca dello Stato, Roma, 1985, pág. 177]. 
No obstante, aparte de las indudables exigencias de orden estrictamente económico financiero, tras la introducción de la legge finanziaria como ley anual "adosada" a la Ley de Presupuestos, laten sin duda otras motivaciones institucionales más genéricas. Ante todo, este nuevo tipo de ley nacía con un propósito de reforzar el papel del Parlamento en el procedimiento de decisión en materia presupuestaria. Por ello, fue concebida en principio como un instrumento tendente a incrementar la participación y el control parlamentario en materia financiera, de modo que el Parlamento, más que como un controlador de decisiones ajenas, pasase a ser protagonista directo, a diferencia de lo que ocurría con la Ley de Presupuestos, donde su margen de enmendabilidad se encontraba innegablemente restringido ${ }^{24}$. Paradójicamente, se acabó diseñando un procedimiento parlamentario ad hoc "motorizado" (dado lo reducido de los plazos de aprobación), en el que, sin embargo, se intentaron evitar hipotéticas veleidades de utilización ajena a sus fines originarios ${ }^{25}$. Así, en prevención de eventuales tentaciones de utilizar la Ley Financiera para incluir en ella las materias más diversas, los reglamentos de las Cámaras fueron reformados, incluyendo medidas extraordinarias de seguridad que evitasen abusos en su utilización ${ }^{26}$. Sin embargo, a pesar de las precauciones introducidas en las sucesivas reformas de los reglamentos de las Cámaras, en la práctica se produjo un abuso de la figura de la Ley Financiera, hasta el punto

24 Pese a todo, ya desde los primeros momentos se hizo patente que la sede donde efectivamente tenían lugar las decisiones parlamentarias relativas a las cuestiones presupuestarias no era el debate plenario, sino las reuniones más restringidas celebradas en la Comisión de presupuestos, las cuales permitían, por una parte, mayor libertad de acción para los parlamentarios y, por otro lado, más flexibilidad para el propio gobierno. Paralelamente, ello tenía un reflejo institucional, al trasladarse el foro de decisión — dentro del propio Parlamento- desde las comisiones parlamentarias sectoriales especializadas, hacia la Comisión de Presupuestos y —en el seno Gobierno- desde los respectivos ministerios hacia el Ministerio de Hacienda (en vez de al Consejo de Ministros colegiadamente). De este modo, las decisiones ya no se tomaban en foros especializados, sino todas de forma global, lo cual, además de resultar poco funcional, conllevaba una notable falta de claridad de las mismas [L. CAPECCHI, "Il rapporto fra le Commissioni bilancio e le Commissioni di settore all'interno del procedimento di esame e di approvazione del bilancio, della finanziaria e delle leggi di spesa", en F. BAssanini y S. MERLini (coords.), Crisi fiscale e indirizzo politico, Il Mulino, Bolonia, 1995, pág. 542]

25 Esto es, básicamente, con el objeto de emplearla para una aprobación más ágil de cuestiones consideradas importantes por el Ejecutivo [A. Manzella, Il Parlamento, Il Mulino, Bolonia, 1991, pág. 262]. Además, recuerda este autor, esta llamada "sesión presupuestaria" goza de una triple garantía: 1) la decisión financiera deberá adoptarse dentro de un plazo fijo; 2) se suspende el restante trabajo parlamentario; 3) si la Comisión de Presupuesto no concluye sus trabajos antes del plazo previsto, el debate en el Pleno versará sobre el texto original del Gobierno; 4) en la Cámara de Diputados se permite que las comisiones comiencen el examen sectorial incluso antes de que el Senado lo haya aprobado en primera lectura.

26 El principal de estos resortes era la previsión de que el Presidente de la Cámara pidiese su parecer a la Comisión de Presupuestos acerca del proyecto, dotándole, asimismo, de un extraordinario poder de inadmisión previo (stralcio), respecto de los elementos extraños a la finalidad de esta ley. De este mismo poder de inadmisión gozaban, además, los presidentes de las comisiones sobre las enmiendas (tanto las parlamentarias como las del Gobierno), que contuviesen materias ajenas [Ibíd., pág. 263]. 
de convertirla en una auténtica ley ómnibus ${ }^{27}$. Muchos vieron en esta fase del procedimiento parlamentario una de las principales causas del fracaso de las leyes financieras, agravada por la sistematicidad del llamado "ciclo electoral del gasto", el cual provocaba una nueva patología del sistema: la práctica tendente a la "compra de votos", de modo que los parlamentarios aprovechaban el trámite de votación de esta ley al final de año, para la introducción de todo tipo de disposiciones de contenido altamente demagógico, las cuales, por si fuera poco, hacían imposible cualquier intento de reducción de los altos niveles de déficit público. Pronto comenzaron a surgir críticas acerca de la falta de seguridad jurídica, de rigor técnico y de respeto al principio democrático ${ }^{28}$. Pero, además, esta acumulación de materias planteaba graves problemas políticos, en cuanto la aprobación de la Ley Financiera suponía una ocasión para "reexaminar todas las decisiones de política económica del gobierno (incluidas las de menor relieve y las más expuestas a las presiones demagógicas), con la consiguiente dificultad de funcionamiento, tanto del parlamento, como del gobierno" ${ }^{29}$. Por último, se criticaba que la Ley Financiera había "desatendido dicha función de trámite entre la programación presupuestaria y su gestión, para asumir la propia de "ley ómnibus" o, en el mejor de los casos, de ley de "Suplencia" y "anticipación" de las normativas sectoriales" ${ }^{30}$.

Por todo ello, pronto se sintió la necesidad de una nueva reforma, de modo que, tan sólo una década después de su introducción, fue aprobada la modificación de ese denostado artículo 11 de la ley 468/78. En efecto, con la ley de 23 de agosto, núm. 362, se proponía como principal objetivo el de reconducir a la Ley Financiera a su sentido original, esto es, el de ser el instrumento normativo que sirviera de nexo operativo entre las previsiones del presupuesto plurianual y las cifras concretas recogidas en el presupuesto para el ejercicio en cuestión ${ }^{31}$. Sin embargo, los contenidos excedentes de la

$27 \mathrm{Al}$ profesor Amato se le atribuyen algunas de las más ocurrentes definiciones de la legge financiaria, tales como "último tren a Yuma", "asalto a la diligencia", "carro de Tespi" o "carrusel infernal".

28 Básicamente, los distintos actores políticos estaban tan ocupados en su juego de negociaciones constantes respecto de las "micro-decisiones", en especial aquéllas relativas al reparto de fondos (dando lugar a lo que se bautizó como "deriva distributiva" de las leyes financieras), donde resultaba mucho más fácil alcanzar un acuerdo, que inevitablemente acabó por no dejarse apenas margen al establecimiento de las grandes políticas y objetivos presupuestarios. [L. VERZICHELli, La legge finanziaria, Il Mulino, Bolonia, 1999, pág. 47].

29 A. Pizzorusso, Manuale di istituzioni di Diritto Pubblico, Jovene, Nápoles, 1997, pág. 523.

30 L. CAPECCHI, "Il rapporto fra le Commissioni bilancio...", cit., pág. 542

31 Así, tras la modificación, se establece que la Ley Financiera "dispone anualmente el marco de referencia financiera para el periodo comprendido en el presupuesto plurianual y provee, para el mismo periodo, a la regulación anual de las cantidades previstas por la legislación vigente al fin de adecuar los efectos financieros a los objetivos" (art. 11, $2^{\circ}$ ). Además, y ahí estriba la auténtica novedad, establece que "la ley financiera no puede contener normas de delegación o de carácter sistemático u organizativo. La misma contiene exclusivamente normas tendentes a producir efectos financieros a partir del primer año considerado en el presupuesto plurianual" (art. $11,3^{\circ}$ que, asimismo, determina el contenido necesario y eventual de la ley en cuestión, mediante la enumeración detallada y taxativa de los contenidos posibles de la misma). Finalmente, la Ley 
Ley Financiera no desaparecieron, sino que se transfirieron a las llamadas "medidas conexas" (provvedimenti collegati), convertidas ya en un concreto status normativo que viene atribuido a aquellos proyectos de ley ordinaria considerados indispensables para la ejecución de la operación presupuestaria prevista por el Gobierno ${ }^{32}$. Obviamente, también respecto de estas normas (pese a no estar incluidas en la sesión parlamentaria del Presupuesto) se suscitaron las mismas acusaciones de falta de rigor técnico y lesividad del principio de seguridad jurídica, especialmente cuando dichas medidas de complemento de la operación financiera eran adoptadas mediante decreto-ley, al final del ejercicio presupuestario previo al de la operación financiera en cuestión ${ }^{33}$. Por ello, enseguida comienza a verse nuevamente como una exigencia la de evitar que el Ejecutivo utilizase este procedimiento "necesario" fuertemente tipificado y basado en la urgencia- para la introducción de reformas estructurales que requerirían de un examen tranquilo y sin presiones por parte del Parlamento ${ }^{34}$. De este modo, pese a que dichos proyectos de "medidas conexas" nunca llegaron a ser un instrumento de incremento irracional del gasto, como ocurría antes con las Leyes Financieras-ómnibus, se trataba de evitar su conversión en un "carril preferente" a disposición del Gobierno para la inclusión de normas sin relación directa e inmediata "con el logro de los objetivos de hacienda pública determinados por las resoluciones parlamentarias " 35 .

Financiera se asimila expresamente a cualquier otra ley ordinaria por cuanto respecta a la necesidad de cobertura financiera. [Para una interesante y detallada descripción de las distintas interpretaciones acerca del alcance del requisito de la cobertura de las leyes financieras tras la reforma de la ley 362/88, cfr. C. FORTE, La riforma del bilancio in Parlamento: Strumenti e procedure, Ed. Scientifiche Italiane, Nápoles, 1994].

32 De este modo, la Ley Financiera pasó a constar simplemente de 6-7 artículos, conteniendo sólo las más esenciales disposiciones. Por el contrario, cada una de las medidas conexas se convirtió en leyes extensas, incorporando "todas las innovaciones sustantivas referidas a la legislación ordinaria", como demuestra el ejemplo de los 267 apartados del art. 1 de la ley 662/1996, de 23 de diciembre [L. Verzichelli, La legge finanziaria, cit., págs. 68 y 100].

33 L. Paladin, Diritto costituzionale, 3a ed., Cedam, Padua, 1998, pág. 367.

34 La nueva regulación perseguía, entre otros, el objetivo de restituir a la legislación ordinaria la competencia de determinar las decisiones básicas ligadas a las políticas sectoriales y, al mismo tiempo, aunque de manera indirecta, devolver a las distintas Comisiones parlamentarias competentes en cada materia su antiguo papel nuclear en el conocimiento de las medidas sectoriales (que hasta entonces se había concentrado en la Comisión de Presupuestos) [L. CAPECCHI, "Il rapporto fra le Commissioni bilancio...", cit., pág. 546 y sigs.]

35 El mayor problema, sin embargo, a la hora de eludir este riesgo de sobrecarga de las leyes conexas, era el hecho de que los límites reglamentarios a la admisión de enmiendas se establecían sólo para las Leyes Financieras, no para las leyes a las que nos referimos, a pesar de que en la práctica, y sólo en algunos ejercicios presupuestarios, lo aplicó también en estos casos la Cámara de los Diputados. Además, no se trataba de una decisión técnica adoptada por los Presidentes de las Cámaras, sino que tenía lugar a través de una votación política igual que para la inadmisión de cualquier enmienda incongruente con el contenido del proyecto. En definitiva, era simplemente una decisión política, dependiente de la voluntad de la mayoría [Vid. M. ZANGANI, "I recenti sviluppi delle procedure parlamentari di bilancio: la terza fase dell'evoluzione in atto", en S. Traversa — A. CASu (coords.), Il parlamento nella transizione, Giuffrè, Milán, 1998, págs.154 y sigs]. 
Finalmente, el último capítulo de esta historia de reformas lo constituye, por el momento ${ }^{36}$, la serie de modificaciones operadas por la ley 208/1999, de 25 de junio, que introduce importantes innovaciones tanto en el calendario del ciclo presupuestario, como en el contenido de los documentos que lo componen $^{37}$. En lo que respecta al tema que nos ocupa, señalar que la Ley Financiera se ha visto enriquecida en su parte normativa con la recuperación de algunos aspectos anteriormente pertenecientes a las "medidas conexas a la operación presupuestaria". En concreto, respecto de la parte normativa, estas modificaciones han hecho superar la configuración que proponía la Ley 468/78 de la Ley Financiera como instrumento de "mera regulación cuantitativan: ahora se permite su asimilación (al menos en lo tocante a los límites de contenido) a la Ley de Presupuestos, y le permite también dictar normas sustantivas tanto con efectos positivos como negativos sobre el Presupuesto ${ }^{38}$. Por el contrario, se le prohíbe expresamente contener normas de delegación, de carácter ordinamental y organizativo (en explícito rechazo al abuso que ciertos gobiernos hicieron de la delegación legislativa en las "medidas conexas" $)^{39}$. Y, por último, de cara a mejorar la seguridad jurídica y la profundidad del examen parlamentario, se exige ya de manera explícita que cada una de las medidas conexas contenga "disposiciones homogéneas por materia". En definitiva, se hace patente la voluntad del legislador de reservar a la operación financiera (manovra finanziaria) y, por tanto, a la llamada sesión presupuestaria, el conjunto de medidas de función no-coyuntural, discutiéndose de ese modo fuera de esta sesión — esto es, durante el primer semestre- las medidas de tipo estructural, para asegurar así un examen parlamentario rápido pero preciso $^{40}$. No obstante, pese a todas las reformas llevadas a cabo, no pa-

36 Aunque aún no hay nada definitivamente aprobado, lo cierto es que actualmente se está viviendo el que sin duda será el cambio más radical de procedimiento presupuestario italiano. Durante la XV Legislatura se inició un largo proceso de reformas de los instrumentos, los medios y los procedimientos presupuestarios. Habrá que esperar a ver los resultados.

37 Cambios éstos simultáneos a la reforma administrativa emprendida con la Ley Bassanini de 1997 e incluso la del sistema electoral, cuyo principal objetivo ha sido el de reforzar la posición del Ejecutivo, para lograr así una mayor estabilidad y continuidad de las líneas políticas acometidas por la mayoría parlamentaria.

38 Para un análisis detallado de esta reforma, vid. N. LuPo, "Le procedure di bilancio dopo l'ingresso nell'Unione economica e monetaria", Quaderni Costituzionali, año XIX, núm. 3, 1999, págs 523-563.

39 Especialmente después de la bochornosa sesión presupuestaria de 1996, cuando los diputados de la oposición abandonaron el Pleno, negándose a participar en la votación de unas medidas que consideraban profundamente lesivas de las competencias parlamentarias por contener una delegación en blanco al Gobierno para desarrollar su indirizzo politico. A partir de ese momento se inicia "un proceso de reacción que incluso traslada el peso del eje del procedimiento legislativo desde las Comisiones al Pleno", a raíz de sendas circulares idénticamente aprobadas por los respectivos Presidentes de las cámaras que van a poner en el centro de la cuestión del procedimiento legislativo el tema de la calidad de la legislación.

40 M. Degni- G. SAlvemini, "L'evoluzione del processo di bilancio dalla legge 468/1978 alla recente riforma", en M. L. BAssi (coord.): Le nuove regole del bilancio statale, F. Angeli, Milán, 2001, pág. 100. 
rece que la situación haya cambiado demasiado. Según parece derivarse de las más recientes críticas doctrinales, la llamada operación financiera (ahora ya sólo constituida por la Ley de Presupuestos y la Ley Financiera) continúa manteniendo ese criticado carácter de medida ómnibus, si bien ahora todo ese aluvión desorganizado de microdisposiciones de tipo distributivo ya no es establecido por el Parlamento, sino que refleja las prioridades del Ejecutivo ${ }^{41}$.

A modo de conclusión, si bien es verdad que tras la reforma llevada a cabo con la ley 362/1988, la Ley Financiera ha perdido ese carácter de ley contenedora de infinidad de medidas de todo tipo, inconexas y que contribuían invariablemente a empeorar los ya alarmantes niveles de déficit público, no es menos cierto que ahora son otras las figuras que ocupan su lugar. Así, con posterioridad a la reforma emerge la figura de las medidas conexas a la operación presupuestaria, donde siguen encontrando cabida una disparidad de medidas que, si bien no suponen ya un riesgo para los niveles de compromiso del gasto, aún carecen de una conexión directa con la materia presupuestaria y versan sobre los temas más heterogéneos. Asimismo, se ha venido incrementando progresivamente el volumen de la Ley Financiera que, sin llegar a los niveles previos a 1988, ha dejado de ser esa breve ley de tan sólo siete artículos. Por otra parte, la propia existencia de las Leyes Financieras sigue siendo altamente discutida en la doctrina debido a los límites tan borrosos que la distinguen (cada vez menos) de la Ley de Presupuestos ${ }^{42}$. Se viene, por tanto, proponiendo cada vez con mayor insistencia, la creación de un único instrumento presupuestario, reestructurado en su formulación para hacerlo más legible y más fácilmente distinguible el contenido discrecional e innovador (que podría ubicarse en una concreta sección, diferente de la meramente recognoscitiva de situaciones jurídicas ya existentes $)^{43}$. La consecuencia que de

41 La acrecentada importancia de estas normas como instrumento definidor de la política gubernamental se debe, ante todo, a la existencia de unos límites temporales para su aprobación, que permiten al Gobierno un mayor control sobre el proceso decisorio, a lo que se añaden las reglas especiales para la admisión de enmiendas, a las que ya hemos hecho referencia con anterioridad. [S. VASSALLO, "Le leggi del governo. Come gli esecutivi della transizione hanno superato i veti incrociati?", en G. CAPANO - M. GIULIANI (coords.): Parlamento e processo legislativo in Italia: Continuità e mutamento, Il Mulino, Bolonia, 2001, pág. 102].

42 En este sentido, se ha puesto de relieve la "crisis de identidad" que la Ley Financiera atraviesa desde el mismo momento de su creación, motivada precisamente por dicho solapamiento con las Leyes de Presupuestos, el cual a su vez tendría origen en esa incorrecta interpretación del art. 81 de la Constitución que ha llevado a conceptuar las Leyes de Presupuestos como leyes meramente formales. En esta línea, Caianello ponía el dedo en la llaga, al denunciar con agudeza la hipocresía de esta situación, originada precisamente por aquéllos que se pretendían "adherir acríticamente a la lectura de esta última norma [art. 81.3 de la Constitución] que ha prevalecido en la costumbre de la Contabilidad más tradicional — lectura que hace decir a la norma más de lo que en ella está escrito, enlazando con la vetusta concepción del presupuesto como ley "formal", incapaz casi por derecho divino de asumir contenidos decisorios..." [Vid. G. CAIANIELLo, "Coordinamento oggetivo e politica di bilancio", en G. Amato-G. MArongIu (coords.), L'amministrazione della società complessa, Il Mulino, Bolonia, 1982, pág. 203].

43 D. MARra, "Legge finanziaria e legge di bilancio", cit., pág. 177. En general, sobre la conveniencia de instituir un único instrumento normativo conteniendo la totalidad de la regulación 
ello se derivaría sería la inmediata simplificación y racionalización del procedimiento parlamentario, aunque lo que no se aclara en estas propuestas, es cómo lograr frenar las tentaciones no sólo del Ejecutivo sino, incluso en mayor medida, del propio Parlamento de acabar convirtiendo también a estas Leyes de Presupuestos "sustantivas» en leyes ómnibus.

B) EE. UU.: LA CONVERSIÓN DE LAS RESOLUCIONES PRESUPUESTARIAS EN LEYES ÓMNIBUS

También en EE.UU., donde el sistema presupuestario es eminentemente parlamentario, se ha venido denunciando en los últimos años la tendencia creciente a transformar las resoluciones presupuestarias en macro-leyes, que se convierten así en vehículo ideal para la regulación de materias completamente ajenas (los llamados "riders") ${ }^{44}$. En efecto, si bien ya desde mediados del s. XIX ambas Cámaras establecieron la prohibición de que las leyes de gastos contuviesen nuevas directivas políticas o modificasen leyes vigentes, tras la reforma del procedimiento presupuestario llevada a cabo en 1974, la llamada "Cláusula de elasticidad" (elastic clause) se ha convertido en la vía de cobertura legal utilizada para la inclusión de un sinfín de disposiciones de lo más variado en las resoluciones presupuestarias ${ }^{45}$. Debido a esta tendencia creciente y preocupante, cada vez se reclama con mayor insistencia desde la doctrina una reforma de la Constitución, bien para introducir la cláusula —ya existente en varias constituciones estatales - de las leyes de objeto único ${ }^{46}$, o bien para reconocer expresamente la figura del "line-item veto" o, lo que es lo mismo, la concesión al Presidente de la facultad de vetar disposiciones concretas dentro de una proposición de ley.

De otro lado, no podemos olvidar que el procedimiento presupuestario sigue siendo un arma decisiva en manos del Congreso para decidir también

financiera, conviene consultar el número monográfico de Quaderni Costituzionali, núm.3, de 1993.

44 En el sistema americano, recibe el nombre de "logrolling" la práctica de incluir en una ley disposiciones carentes de relación con la misma, que adolecen de apoyo mayoritario por sus propios méritos para lograr su aprobación, por lo que vienen "camufladas" dentro del conjunto del proyecto. Un "rider" es una especie dentro del género anterior pero, en este caso, incluida en un proyecto de ley de contenido presupuestario (bien sea una ley de gasto, una resolución presupuestaria o una ley de reconciliación) cuya aprobación está virtualmente asegurada.

45 Se trata simplemente de una cláusula bastante general y abierta, que permite al Congreso incluir en este tipo de resoluciones "aquellas otras materias relacionadas con el presupuesto que puedan resultar convenientes para llevar a cabo los propósitos de esta Ley" [Art. 301 b) 2) de la Congressional Budget Act de 1974], lo cual ha servido sobre todo como medio habitual para la realización de reformas procedimentales.

46 B. P. Denning - B. R. Smith, "Uneasy riders: The case for a truth-in-legislation", Utab Law Review, 1999, págs. 957 y sigs; J. P. SсHuck, "Returning the one to Ohio's one-subject rule", Capital University Law Review, núm. 28, 2000, págs. 901-902. Ya a finales de los años 50 se planteaba el problema prácticamente en los mismos términos que hoy en día [Vid. M. H. Ruud, "No Law Shall Embrace More Than One Subject", Minnessotta Law Review, núm 42, 1958, págs. 389 y sigs.] 
cuestiones de política material, mediante los llamados «limitation riders". Se trata de disposiciones contenidas en leyes generales de asignación, que prohíben el gasto para propósitos específicamente determinados ${ }^{47}$. Básicamente, con ello se pretende encontrar un equilibrio entre dos principios distintos y, en cierto modo, contrapuestos. Por un lado, el principio de separación de la asignación de los gastos respecto de la función legislativa y, por otro, la facultad del Congreso de decidir no destinar fondos (total o parcialmente) a una agencia, un programa o un objetivo concretos, aunque éstos ya gocen de la previa autorización legal. Dichas disposiciones han ido extendiéndose a una amplia variedad de temas y su uso creciente se ha convertido en fuente de preocupación en el Congreso, hasta el punto de que en 1983 la Cámara de los Representantes aprobó una serie de procedimientos destinados a restringir la proliferación de este tipo de enmiendas.

Pero centrándonos ya en el tema general de la frecuente inclusión de legislación material en la legislación presupuestaria, hay que comenzar señalando la especial incidencia de este fenómeno en las llamadas leyes de reconciliación ${ }^{48}$. Y ello por el simple motivo de que, al no incluir el procedimiento de reconciliación ningún resorte con el que el Congreso pueda forzar la cooperación del Presidente, sólo le queda acudir a "manipulaciones estratégicas". De este modo, una de las principales armas de que dispone el Congreso consiste en vincular la legislación derivada de la

47 Estas disposiciones, no obstante, deben reunir tres requisitos: 1) no pueden imponer deberes ni cargas adicionales en funcionarios públicos, 2) ni interferir en la competencia discrecional de los mismos, 3) ni exigir de estos la adopción de valoraciones o decisiones no exigidas previamente por la ley.

48 El procedimiento de reconciliación (Reconciliation Process) es uno de los elementos que integran el procedimiento presupuestario en el Congreso, cuya característica principal viene dada por su tramitación preferente, con reglas especiales, tendentes a agilizar la aprobación en el Pleno. Este trámite, destinado a que el Congreso pudiese introducir modificaciones en la legislación existente en materia de impuestos y prestaciones (el término reconciliación aquí viene referido a un proceso de ajuste entre los ingresos y gastos existentes y aquéllos previstos en la resolución presupuestaria), debía adecuar el Presupuesto total a los objetivos fijados en la última de las dos resoluciones presupuestarias que el Congreso aprobaba anualmente. Se concebía, por tanto, como una figura a modo de conclusión final, que debía realizarse al término de todo el procedimiento presupuestario. En el sistema diseñado por la Ley de 1974, realmente, la reconciliación no se preveía una figura especialmente relevante: de hecho, sólo en el supuesto de que la segunda de las resoluciones presupuestarias decidiese un incremento o disminución en los niveles de ingresos y gastos para prestaciones sociales, la Ley de 1974 permitía al Congreso incluir las llamadas "instrucciones de reconciliación" (reconciliation instructions). En realidad, dichas instrucciones estaban concebidas como simples sugerencias dirigidas a las comisiones implicadas, de cara a la futura redacción de las proposiciones de ley necesarias para lograr dichos objetivos presupuestarios. No obstante, en los años ochenta la reconciliación se convierte en una figura crucial del procedimiento presupuestario, al dotársela de un mayor carácter innovador y vinculante, unido a la creciente implicación de la Casa Blanca en la elaboración del Presupuesto parlamentario, con el resultado de que ambos órganos se han hecho progresivamente más interdependientes y que el equilibrio del poder presupuestario se ha vuelto inestable. En general, sobre la evolución del sistema presupuestario estadounidense, permítase la remisión a I. M. GIMÉNEz SÁNCHEz, Las competencias presupuestarias del Parlamento, CEPC, Madrid, 2008, págs. 105-132. 
reconciliación a determinados componentes necesarios del procedimiento presupuestario, para exigir así al Presidente la aprobación del conjunto ${ }^{49}$. Además, sin duda, las mismas especialidades procedimentales de la reconciliación que en su día hicieron de dicho proceso una herramienta efectiva para combatir el déficit, se convirtieron pronto en un atractivo reclamo para que las comisiones parlamentarias incluyesen decisiones y propuestas no presupuestarias, con el objeto de apartarlas del procedimiento legislativo ordinario, de las prácticas de obstruccionismo e, incluso, de la posibilidad de ser objeto de enmiendas.

En concreto, son tres las limitaciones legales que básicamente presenta la participación parlamentaria respecto del procedimiento de reconciliación: los plazos, la restricción a la admisibilidad de las enmiendas, y el límite de veinte horas de duración del debate. De todas ellas, es en esta última en la que la doctrina americana viene haciendo un mayor hincapié a la hora de criticar la inclusión de "riders" en la legislación presupuestaria. En efecto, se considera que la restricción del tiempo de debate — cuyo propósito no es otro que el de prevenir las tradicionales prácticas de obstruccionismo partidista - opera como una fortísima limitación práctica ${ }^{50}$. Especialmente en el Senado, donde sólo se permiten veinte horas de debate para la discusión de la resolución presupuestaria (exactamente doce minutos por senador) antes de pasar a su votación. De este modo, la extensión del debate resulta inversamente proporcional a la trascendencia de los cambios políticos que habitualmente incorpora la legislación de reconciliación. Por último, la tramitación urgente y en consecuencia superficial, lo convierte en el vehículo perfecto para la inclusión de aquellas medidas que no interesa someter a un debate en profundidad y que, de esta manera, consiguen pasar desapercibidas, ocultas en medio de un aluvión de materias absolutamente dispares ${ }^{51}$.

Tradicionalmente se ha identificado el momento de aprobación de las resoluciones presupuestarias como aquél donde un elevado porcentaje de parlamentarios aplica un principio conocido como "pork barrel ethic", que implica votar por las propuestas ajenas con independencia de su oportunidad, en la confianza de recibir idéntico favor como contraprestación. Una actitud ésta que, ejercida sin autocontrol por todos los parlamentarios, podría llegar a

49 Véase, A. S. Krishnakumar, "Reconciliation and the fiscal Constitution: The anatomy of the 1995-96 Budget "train wreck"', Harvard Journal on Legislation, núm. 35, 1998, pág. 612.

50 Pese a la enorme extensión de las proposiciones de ley de reconciliación, normalmente la Comisión Reglamentaria de la Cámara de Representantes sólo permite considerar media docena de enmiendas, entre ellas la enmienda a la totalidad presentada por la minoría, de modo que la resolución final casi siempre se aprueba sin sufrir apenas variaciones.

51 Un ejemplo paradigmático lo encontraríamos en el debate de la resolución presupuestaria de 1996, donde prácticamente ningún parlamentario pudo leerse, con anterioridad a su votación en el Pleno, las casi 2000 páginas de que constaba el proyecto, pese a lo cual no se convocaron debates acerca de las consecuencias y beneficios del mismo. Incluso los propios líderes de la mayoría tuvieron problemas para entender y explicar ciertas partes del proyecto y de las enmiendas propuestas. [Ibíd., pág. 617] 
justificar cualquier esquema de gasto concebible ${ }^{52}$. La principal objeción es que este procedimiento no permite una discusión y un debate serios y rigurosos sobre las distintas materias incluidas como "riders" en las medidas ómnibus del procedimiento de reconciliación. Así, ocurre a menudo que sólo con posterioridad los parlamentarios adquieren conciencia de lo que han votado, llevándose en ocasiones desagradables sorpresas ${ }^{53}$. Por ello, incluso aquéllos que defienden que el poder presupuestario del Congreso — el famoso power of the purse - es casi absoluto, reconocen que este procedimiento especial de asignación presupuestaria no es el adecuado para emprender transcendentes actuaciones políticas sustanciales, ni para establecer prioridades nacionales ${ }^{54}$. De hecho, los propios Reglamentos parlamentarios constituyen un reflejo de esta preocupación, por lo que siempre se ha intentado separar el procedimiento de distribución de fondos públicos del resto de los procedimientos legislativos. Básicamente, los principales riesgos que presenta la confusión de ambas actividades viene dado precisamente por las peculiaridades del procedimiento presupuestario que, de entrada, impide la intervención de las distintas comisiones legislativas y, además, dadas las premuras de este tipo de procedimiento, dificulta un adecuado debate parlamentario de las distintas medidas incluidas en ella. En definitiva, si bien no existe una explícita limitación constitucional al uso de las resoluciones presupuestarias como vehículo para la inclusión de "riders" que establezcan disposiciones de contenido material, lo cierto es que dichos "riders" están sometidos a las mismas limitaciones constitucionales que cualquier otro tipo de legislación. Desde este punto de vista, con frecuencia son acusadas de violar concretas disposiciones constitucionales, principalmente el principio de separación de poderes ${ }^{55}$.

52 Con la expresión "pork-barrel" se hace referencia a aquellas partidas de gastos incluidas en el Presupuesto federal "para servir sólo a intereses particulares y que se hacen por representantes federales para comprar el apoyo local".

53 Resulta especialmente significativo y preocupante el abuso que de esta figura se ha hecho para la regulación de materias medioambientales, con el objetivo primordial de eludir un debate público con detenimiento. No es de extrañar, por tanto, que la mayoría de los comentarios doctrinales relativos a la naturaleza de los "riders" y al contenido de las Leyes de Presupuestos se encuentren en revistas jurídicas dedicadas al medioambiente. Uno de los casos más polémicos fue el de la introducción de un "rider" en la Balanced Budget Reconciliation Act de 1995, que permitía la explotación petrolífera y gasística en las reservas naturales del Ártico. Esta medida ya había sido extensamente discutida por el Parlamento con anterioridad, habiendo sido siempre rechazada por una amplia mayoría de la Cámara (incluida una gran parte del sector republicano). Sin embargo, su inclusión en la resolución presupuestaria consiguió evitar la publicidad y las garantías procedimentales del procedimiento legislativo ordinario. [Para un completísimo estudio de la evolución de esta situación, véase R. J. LAZARus, "Congressional descent: The demise of deliberative Democracy in Environmental Law", Georgetown Law Journal, núm. 94, marzo 2006, págs. 619 y sigs.]

54 N. E. Devins, "Budget reform and the balance of powers", William and Mary Law Review, núm. 31, verano 1990, pág. 458.

55 En este sentido, ha sido especialmente criticada la utilización de los "riders" para incluir instrucciones y directivas a la Administración, excediéndose así de su competencia legislativa para entrar de lleno en el ejercicio de la función de dirección de la política interna y, por tanto, vulnerando el principio de separación de poderes al ejercer una competencia constitucionalmente atribuida al poder Ejecutivo. [J. B LeBoeuf, "Limitations on the use of appropriation riders by Con- 
Por todo lo expuesto, cada vez surgen con mayor fuerza - como ya avanzábamos al inicio de esta exposición - las propuestas de reforma de la Constitución que, básicamente, siguen dos direcciones distintas. En primer lugar aquéllos que defienden la necesidad de añadir una enmienda que exija que las leyes del Congreso sólo puedan tratar de una materia única, que debería, además, venir recogida expresamente en el título de la misma. Esta cláusula ya existe en varias de las Constituciones de los Estados, como Tennesse y Ohio. Dicha doctrina sostiene que de esta manera se controlaría el gasto público: al limitar el "pork barrel", se mitigaría el fenómeno de legislar a través de "riders", se restringiría la legislación-ómnibus fomentada por el "logrolling" y, sobre todo, se potenciaría la responsabilidad política institucional del Congreso y sus miembros, al cumplirse los principios de publicidad y debate, necesarios en todo procedimiento legislativo. En definitiva, si bien es cierto que el reglamento del Congreso ya contiene normas limitativas, en la práctica éstas son como papel mojado, por lo que una reforma de la Constitución tendría un mayor poder coercitivo, al ser incluso exigible su cumplimiento ante los tribunales ${ }^{56}$.

La segunda de las reformas constitucionales reclamadas, en cambio, defiende la introducción de un poder de veto selectivo cuyo titular sería el propio Presidente. En realidad esta propuesta, más que solucionar el problema, pretende situar al Presidente en una situación de equidad respecto del Congreso, devolviéndole una "igualdad de armas" de la que gozaba antes de la aparición de estas reconciliaciones-ómnibus, plagadas de "riders", que se ve obligado a pasar, si no quiere quedarse sin las necesarias asignaciones de gastos $^{57}$. Esta medida, no obstante, es objeto de fuertes polémicas, por cuanto resulta sospechosa de vulnerar el rígido sistema de separación de poderes es-

gress to effectuate substantive policy changes", Hastings Constitutional Law Quarterly, núm. 19, 1992, pág. 463] Asimismo, también en relación con la lesión del principio de separación de poderes, se ha denunciado que "[l]os intentos del Congreso de eludir los requisitos del Artículo I, Sección 7 sobre el bicameralismo y la presentment clause también representan una usurpación de poder excediendo claros límites constitucionales(...) Aquí, en vez de intentar realizar el trabajo de otro (ejecutar el Derecho), el Congreso intenta hacer su propio trabajo (legislar), pero sin las limitaciones del bicameralismo y la presentment clause. Al excluir al Presidente del procedimiento legislativo, el Congreso amenaza, en estos casos, con concentrar el poder en sus propias manos, de una manera potencialmente peligrosa" [A. S. GREENE, "Checks and balances in an era of presidential lawmaking", University of Chicago Law Review, núm. 61, invierno 1994, págs. 123 y sigs.]

56 B. P. Denning- B. R. SMith, "Uneasy riders: The case for a truth-in-legislation", Utah Law Review, 1999, págs. 968 y sigs.

57 Esta postura del Congreso es, en cierto sentido, una especie de ultimátum, que funciona como un "farol" en el póquer. [E. GARRET, "Accountability and restraint: The federal budget process and the line-item veto", Cardozo Law Review, núm. 20, enero 1999, págs. 913 y sigs]. En este caso, sin embargo, la crítica no vendría referida en sí a las leyes de autorización de gastos, sino a la posibilidad de que, mediante la inclusión de un alud de materias dispares en las mediadas ómnibus, se obligase al Presidente a una especie de "O-lo-tomas-o-lo-dejas", sin una correspondiente facultad de veto particular sobre cada una de las medidas. En contra, vid. N. Devins ["Budget reform and the balance of powers", cit., págs. 1018 y sigs.] que considera que transferir poderes presupuestarios al Presidente vulneraría el principio mayoritario e implica partir del prejuicio de que el Presidente "sabe más" de la materia presupuestaria. 
tablecido en la Constitución americana ${ }^{58}$. De hecho, en 1996, el Congreso aprobó una ley que otorgaba al Presidente una forma de veto selectivo (Line Item Veto $A c t$ ), la cual fue finalmente declarada inconstitucional por el Tribunal Supremo en junio de 1998 (Clinton vs. City of New York, 524 U.S. 417, 1998). En esta sentencia, la mayoría del Tribunal, siguiendo una interpretación bastante formalista del art. I de la Constitución, no considera que la competencia de veto signifique el ejercicio de un poder discrecional concedido al Presidente por el propio Congreso, ni equiparable a la potestad de no efectuar gastos ni ingresos autorizados por el Congreso, sino que — según la mayoría del Tribunal- el conceder al Presidente la facultad de suprimir in toto fragmentos de proposiciones de leyes, equivalía a concederle la capacidad de legislar. En definitiva, la conclusión del fallo fue que para lograr el resultado deseado (esto es, atribuir al Presidente la facultad de vetar fragmentos determinados de una ley) al Congreso no le bastaba con aprobar una ley, sino que - al tratarse de una modificación del papel del Presidente en la función legislativa - se requería una reforma de la Constitución. Y esta reforma constitucional es precisamente lo que reclaman ahora los partidarios de la atribución al Presidente del "line-item veto" 59 .

Sin embargo, no hay que olvidar que, en el sistema americano, el problema de la inclusión de disposiciones legislativas de lo más variado dentro de leyes que debieran ser exclusivamente referidas a la materia presupuestaria tiene un significado esencialmente diverso del que posee en los sistemas presupuestarios continentales. Diferencia que, necesariamente, viene dada por la caracterización del sistema presupuestario estadounidense como un sistema donde la competencia efectiva en materia de decisión presupuestaria corres-

58 A lo largo de los años, los Presidentes americanos han venido lamentándose de su situación de desventaja, al verse obligados a firmar (o vetar) la ley completa, sin poder rechazar disposiciones concretas. Una situación que se ve agravada cuando dichas leyes llegan a sus manos una vez que el año fiscal ya ha comenzado — con el riesgo de paralización de la actividad estatal que un eventual veto supondría. Y para empeorar las cosas, el Congreso debilita su capacidad de veto añadiendo numerosas leyes de asignación de gasto, junto con legislación material, en una medida ómnibus. [J. B. Leboeuf, "Limitations on the use of appropriation riders...", cit., págs. 457 y sigs].

59 No se trata en absoluto de una cuestión irrelevante, puesto que el debate acerca de la conveniencia o no de conceder al Presidente la facultad de veto selectivo, ha sido el eje que ha venido centrando los principales argumentos acerca de la más amplia cuestión del reparto de poderes entre el Legislativo y el Ejecutivo, especialmente en materia presupuestaria. De ello es muestra, asimismo, la ingente bibliografía existente al respecto, de la que aquí sólo mencionaremos alguna de sus principales contribuciones: J. S. KenNEDY, "How a bill does not become a law: The Supreme Court sounds the death knell of the Line Item Veto Act, Mississippi College Law Review, núm. 20, 2000, págs. 357 y sigs.; M. T. KuINE, "The Line Item Veto Case and the Separation of powers", California Law Review, núm. 88, 2000, págs. 181 y sigs.; A. R. Petrilla, "The role of the Line Item Veto in the Federal balance of power", Harvard Journal on Legislation, núm. 31, 1994, págs. 469 y sigs.; B. Powell, "Line Item Veto", Harvard Journal on Legislation, núm. 37, 2000, págs. 253 y sigs.; E. S. SchmitT, "There is no joy in D.C., the mighty Court struck out: An analysis of Clinton v. City of New York, The Line Item Veto Act and the Court's failure to uphold constitutionally legitimate means to a viable end", Saint Louis University Law Journal, núm. 44, 2000, págs. 167 y sigs. 
ponde al Congreso. Por ello, la discusión de esta cuestión forma parte de todo un paquete de propuestas de reforma de la llamada "constitución financiera", dirigidas no tanto a proteger las competencias del Parlamento frente a ataques o invasiones del Ejecutivo (que, en este caso, es otra "Víctima" más), sino que responde a una defensa del propio sistema y de los intereses de la colectividad frente a los abusos del poder legislativo. En efecto, todas las propuestas formuladas en los últimos años han tenido como común denominador la búsqueda del interés público en la adopción de las decisiones parlamentarias, intentando superar el actual partidismo y particularismo que caracteriza al Congreso en las mismas ${ }^{60}$. Pese a todo, en último término no se trata de condenar el uso de los "riders" per se, sino de establecer un correcto uso de los mismos, que no implique una vulneración de los valores protegidos por el procedimiento legislativo ordinario. Es obvio que su uso está muy lejos de lo que sería el óptimo método de legislación, por cuanto "obvia muchos de los elementos tradicionales del procedimiento legislativo que aseguran que las leyes sean aprobadas bajo el ojo público y persiguiendo el interés público" ${ }^{61}$. Pero tampoco cabe desconocer que estamos ante una figura que siempre ha existido y que, al fin y al cabo, está sometida a un procedimiento de aprobación parlamentaria y de posterior control jurisdiccional. Se trata, en definitiva, de prevenir no tanto contra el uso de los riders, sino de denunciar la dificultad de llevar a cabo una adecuada deliberación y aprobación de toda una ley (especialmente en el caso de una ley ómnibus) basada en una sucesión incoherente de riders, que no permite un correcto conocimiento y publicidad de las medidas en ella contenidas, lo cual a su vez constituye el motivo por el que resulta tan fácil "colar" los riders subrepticios (conocidos como "píldoras envenenadas" $)^{62}$. En definitiva, parece que la solución última tendería más bien a instar a un auto-sometimiento del Congreso a sus propias reglas, cumpliendo las normas de congruencia y respetando los principios de publicidad, debate y pluralismo político inherentes al procedimiento legislativo ordinario $^{63}$.

60 Nos referimos no sólo a aquellas propuestas de enmiendas de la Constitución para exigir el equilibrio presupuestario, el line item veto o las leyes de contenido único, sino incluso, las de más amplio espectro, como las referidas a la financiación de las campañas políticas o la fijación de límites temporales a las sesiones parlamentarias.

61 "Más que condenar el uso de riders en general, como una cuestión de nitidez blanca y negra, debería admitirse la naturaleza ambigua, gris, de los riders y desarrollar una serie de criterios para su consideración" [J. M. PATLIS, "Riders on the storm, or navigating the crosswinds of appropriations ad administration of the Endangered Species Act: A play in five acts", Tulane Environmental Law Journal, núm. 16, verano 2003, págs. 261 y 322].

62 También en el caso americano, las calificaciones atribuidas a este tipo de macroleyes son de lo más pintorescas: "legislative juggernaut", "elephantine monstrosity", "a Frankenstein creature...patched together from old legislative body parts that don't quite fit, "must-pass bill(...)magnet for all manner of legislative desiderata — from major policy changes to parochial local projects", "vehículo para leyes que los parlamentarios no terminarían de otro modo"...

63 Todo ello sin olvidar, por último que, en realidad, esta confusión entre leyes de gasto y leyes de autorización (equivalente en nuestro sistema a la tendencia de legislar a través de las leyes de presupuestos o asimilados) no es más que el reflejo de la incapacidad del Congreso de 


\section{C) Francia: El CONTROL DEL DESBORDAMIENTO NORMATIVO MEDIANTE EL CONTROL CONSTITUCIONAL}

El caso francés se presenta más complicado de describir en su situación actual, a la vista de la reforma total sobre el sistema y el procedimiento presupuestarios llevada a cabo por la Ley Orgánica relativa a las leyes de presupuestos de $2001^{64}$.

Por otra parte, en un estudio de la jurisprudencia constitucional, se aprecia fácilmente un fuerte incremento de las disposiciones declaradas inconstitucionales por este motivo a partir del año $2000^{65}$. Hasta ese momento, debido sobre todo al rigor con el que el Consejo Constitucional había venido interpretando las disposiciones de la Ordenanza de 1959 en las que se establecía el ámbito material de las leyes de presupuestos ${ }^{66}$, puede decirse que la cuestión de las macroleyes de presupuestos (o sus sucedáneos) no se había planteado como un problema especialmente preocupante en el sistema de fuentes francés ${ }^{67}$. A ello, sin duda, también ha contribuido el peso de la tradición, ya que en la III ${ }^{\mathrm{a}}$ y $\mathrm{IV}^{\mathrm{a}}$ Repúblicas se recogía expresamente la prohibición de los llamados "cavaliers budgétaires", esto es, se impedía la inclusión de disposiciones ajenas a la materia presupuestaria en las lois de finances ${ }^{68}$. En general, la justificación teórica de la prohibición de los cavaliers bugétaires siempre ha venido basándose, de una parte, en el principio de unidad presupuestaria y, de otra, en la necesidad de mantener la pureza del procedi-

aprobar leyes de autorización. Esto ha sido interpretado por algunos autores como una preferencia del Congreso en la práctica por la faceta de control antes que la legislativa. Una tendencia que puede revelarse especialmente peligrosa en un sistema como el estadounidense - caracterizado por una rígida separación de poderes - si el Congreso entra en un excesivo detalle respecto de la regulación del funcionamiento y la actuación de la Administración. Si bien el uso de las asignaciones presupuestarias como método de injerencia en la actividad interna de la Administración es considerada como una técnica más de control parlamentario, en la práctica se trata de un arma especialmente poderosa. Y ello porque, a diferencia de las demás — que se basan en una amenaza de acción- en este caso se trata del ejercicio parlamentario de una acción directa sobre la esfera de la Administración. Véase, N. E. Devins, "Budget reform and the balance of powers", cit., págs. 459 y sigs.

64 Nos referimos a la transformación crucial de todo el procedimiento presupuestario llevada a cabo por la Ley Orgánica núm. 2001-692 de 1 de agosto, relativa a las leyes de presupuestos (Loi organique relative aux lois de finances, en adelante, LOLF)

65 R. DÉCHAUX, "L'évolution de la jurisprudence constitutionnelle en matière de "cavaliers" entre 1996 et 2006", www.conseil-constitutionnel.fr/divers/documents/cavaliers.pdf (consultado a fecha 10 de junio de 2008)

66 Durante casi medio siglo, la Ordonnance de 2 de Enero de 1959 fue el texto básico de regulación de la materia presupuestaria y que — no obstante los numerosos intentos de reformareguló el sistema presupuestario francés, sin sufrir apenas modificaciones, durante las últimas cuatro décadas, llegando a ser considerada como la "constitución financiera de Francia".

67 J. VAlLs, Le contrôle des normes législatives financières par les Cours Constitutionelles espagnole et française, LGDJ, París, 2002, págs. 74 y sigs.

68 Sin embargo, a pesar de esta prohibición explícita, la práctica de los "cavaliers" no ha cesado a lo largo de los siglos. [M. C. Bergères, "Les cavaliers budgétaires", Revue de Droit Public et de la Science Politique en France et à l'etranger, julio-agosto 1978, págs. 1373 y sigs]. 
miento legislativo presupuestario - asegurándose así tanto el cumplimiento de los plazos de aprobación como la propia coherencia del debate. En otras palabras, se ha derivado del art. 34 de la Constitución de 1958 (que establece que "Il]as Leyes de Presupuestos establecerán los ingresos y los gastos del Estado en las condiciones y con las reservas establecidas por una ley orgánica"), así como de los arts. 1 y 31 de la Ordenanza. El primero de ellos, donde se definía genéricamente el contenido de las leyes de presupuestos y el otro, que concretaba sus tres posibles ámbitos materiales: obligatorio, facultativo-exclusivo y compartido. En este punto no se han introducido grandes cambios con la LOLF de 2001, cuyo art. 34 (en el que se mantiene la misma estructura de las Leyes de Presupuestos anuales escindida en dos partes) ofrece una definición aún más precisa del triple campo competencial de la Ley de Presupuestos $^{69}$. Así, resulta comúnmente admitido doctrinal y jurisprudencialmente que la prohibición de los "cavaliers budgétaires", tiene por objeto evitar una inflación de los proyectos y, en consecuencia, un considerable entorpecimiento de los debates presupuestarios. De este modo, la protección del contenido de las Leyes de Presupuestos se presenta como "un complemento natural de los estrictos plazos constitucionales y de los procedimientos previstos en el artículo 47 de la Constitución", lo cual juega a favor del propio interés del Parlamento, al evitar que ciertas disposiciones - completamente ajenas al ámbito presupuestario - puedan beneficiarse de procedimientos de aprobación específicos, más restrictivos para las Cámaras que el previsto para la legislación ordinaria ${ }^{70}$.

Decíamos antes que éste es uno de los puntos en los que el Consejo Constitucional ha extremado su atención a la hora de llevar a cabo un control de la constitucionalidad de las leyes de presupuestos, tal como viene haciendo desde su primer pronunciamiento (DC 74 de 28 de diciembre de 1976). Circunstancia fomentada por el hecho que si el Consejo Constitucional encuentra alguna disposición "ajena al objeto de las leyes de presupuestos" —es decir, que no encaja en ninguno de los tres ámbitos materiales legalmente previstos- puede apreciar la inconstitucionalidad de oficio. En este sentido, más allá de cualquier interpretación acerca del alcance de la admisibilidad de las enmiendas, en realidad "el problema de los cavaliers gubernamentales es un problema de constitucionalidad y no de admisibilidad. Un cavalier es una

69 De hecho, el Consejo de Estado, en su dictamen de 21 de diciembre de 2000 (relativo a la propia LOLF), advertía que "sería contrario al objetivo de respeto de los derechos del Parlamento que la redacción de la ley orgánica permitiese atraer en las leyes de presupuestos, que se votan según el procedimiento de urgencia, disposiciones cuyo objeto principal no sea financiero". Asimismo, respondiendo a la cuestión de si la ley orgánica podría establecer que las Leyes de Presupuestos contuviesen disposiciones dirigidas a "organizar la información y el control del Parlamento sobre la gestión de la hacienda pública", admite que ello sería posible, si bien, "habida cuenta de la urgencia ligada a la votación de las leyes de presupuestos" no cabría reservar tales disposiciones a dicha categoría de ley, restringiendo así el ámbito de las leyes ordinarias.

70 Aunque algunos de los "cavaliers budgétaires" anulados por el Consejo Constitucional procedían de iniciativas del Gobierno, lo cierto es que el Consejo tiende a extremar su severidad respecto del control parlamentario sobre los gastos públicos. 
iniciativa ajena al ámbito de las leyes de presupuestos, que se aprovecha del procedimiento acelerado propio del examen de este tipo de leyes para entrar en el derecho positivo, cuando habría debido seguir el procedimiento ordinario de elaboración de las leyes. El problema planteado es, por tanto, el de la constitucionalidad del procedimiento legislativo seguido ${ }^{71}$. Para llevar a cabo dicho juicio de inconstitucionalidad, el Consejo emplea como parámetro de validez las disposiciones contenidas en la LOLF de 2001 (antes la Ordenanza de 1959), en cuanto normas integrantes del llamado bloque de la constitucionalidad $^{2}$, y a la que se remite expresamente el art. 34 de la Constitución.

Puede afirmarse, en líneas generales, que el Consejo admite la inclusión de toda disposición con una "incidencia directa e inmediata sobre las cargas y los recursos del Estado" ${ }^{73}$, concepto normativo indeterminado que, sin embargo, viene interpretado de una manera cada vez más laxa. A pesar de todo, se considera que la introducción del requisito de la "inmediatez" ha logrado evitar una situación de flexibilidad absoluta, constituyéndose así en límite efectivo frente a la práctica inclusión de cualquier tipo de norma ajena al ámbito de competencia de las leyes de presupuestos. Por otra parte, en una primera fase, hasta 1981, el Consejo Constitucional hacía derivar esta restricción del contenido de las leyes de presupuestos de la limitación del derecho de enmienda establecida en el art. 42 de la Ordenanza, para posteriormente derivarla de manera directa del art. 1 (también de la Ordenanza), esto es, de la norma que define el contenido de las leyes de presupuestos ${ }^{74}$. Parece así que el Consejo Constitucional se ha ido aproximando cada vez más a esta postura. Además, de modo específico, el Consejo ha insistido en que al igual que una ley orgánica no puede contener disposiciones correspondientes al ámbito exclusivo de las Leyes de Presupuestos (DC 355 de 10 de enero de 1995), tampoco podrá una Ley de Presupuestos contener materias de naturaleza orgánica (DC 386 de 30 de diciembre de 1996).

71 D. STRAuss-Kahn, "Réflexions sur l'application de la loi organique par le Parlement”, Revue Française de Finances Publiques, núm. 26, 1989, pág. 56. En este mismo sentido, véase el detallado análisis acerca de la oponibilidad de la excepción del art. 42 de la Ordenanza a los contenidos presentados por el Gobierno, en C. Goux, La Constitution et l'initiative financiére des deputés, La Documentation Française, París, 1984, págs. 113-118.

72 A pesar de que la Corte Constitucional incluyó las leyes orgánicas dentro del «bloque de la constitucionalidad" (DC 60-8 de 11 de agosto de 1960), existe una seria discrepancia doctrinal respecto de la inclusión (o no) de la ley orgánica relativa a las leyes de finanzas en el bloque de la constitucionalidad. En la práctica, sin embargo, la Ordenanza de 1959 ha sido el principal parámetro que ha utilizado la Corte en su control de conformidad de las leyes de presupuestos a la Constitución [Vid. F. Rubio Llorente - L. Favoreau, El bloque de la Constitucionalidad, Civitas, Madrid, 1991, pág. 37].

73 DC 330 de 29 de diciembre de 1993 y DC 385 de 30 de diciembre de 1996. Pueden encontrarse varios ejemplos de la concreta aplicación de la jurisprudencia de la Corte en L. PHILIP, "L'ordonnance du 2 janvier 1959 portant Loi Organique relatif aux Lois de Finances", La documentation française, núm. 5.01, 1998, pág. 7; y L. FAVOreu— L. PhILIP, Les Grandes décisions du Conseil Constitutionnel, 10a ed, Dalloz, París, 1999, págs. 895 y sigs.

74 L. Favoreu- L. Philip, Les Grandes décisions du Conseil Constitutionnel, cit., pág. 906. 
Por otra parte, se ha puesto de manifiesto una creciente tendencia por parte del Gobierno a respetar los límites de contenido de las leyes presupuestarias. En efecto, si bien en los primeros años era el Ejecutivo - y, de manera especial el Ministerio de Educación(?!)— quien aprovechaba la rapidez y seguridad del procedimiento presupuestario para incluir las más variadas disposiciones de contenido no-financiero en el proyecto de Ley de Presupuestos, en la actualidad la mayoría de las disposiciones constitucionalmente anuladas proceden de enmiendas parlamentarias incorporadas a lo largo del procedimiento de aprobación ${ }^{75}$. De cualquier manera, parece existir una suerte de connivencia entre el Gobierno y el Parlamento, que en la práctica han conducido a una paralización de la censura de estos "cavaliers". Para salvar dicha interdicción, en diversas ocasiones se ha acudido a una técnica similar a la de nuestras Leyes de Acompañamiento, agrupando «aquellos añadidos relativamente menores que no son verdaderamente normativos" en una ley distinta de la Ley de Presupuestos, pero que se presenta simultáneamente. Esta técnica de la ley relativa a "diversas disposiciones de orden económico y financiero" o "diversas disposiciones de orden social" (o, más coloquialmente, leyes "fourre-tout"), ha sido empleada en varias ocasiones, sin que ello haya evitado completamente que las Leyes de Presupuestos se vean sobrecargadas con materias ajenas a su propio objeto ${ }^{76}$. En este sentido, aunque la doctrina admite que estas leyes no están sometidas a los requisitos de limitación de contenido establecidos para las Leyes de Presupuestos, sí se percibe una especial inquietud ante la posibilidad de que dichas leyes pudieran afectar a la coherencia de la política financiera del Gobierno contenida en la Ley de Presupuestos.

Dicho recurso a las leyes de contenido vario en materia económica ya había sido utilizado durante los primeros años de la IV a República, cayendo posteriormente en desuso hasta que, a finales de los años ' 60 , debido a la necesidad de encarar una grave crisis económica, se plantea, asimismo, la conveniencia de racionalizar el trabajo parlamentario, retornándose a esta práctica $^{77}$. Por otra parte, hay que recordar que a partir de 1996 se introduce la figura de las Leyes de Financiación de la Seguridad Social (LFSS), siguiendo el modelo de la Ley de Presupuestos. También aquí se proscribe la figura de los "cavaliers sociaux", con dos objetivos: primero, garantizar la coherencia y la calidad de los debates parlamentarios y, además, impedir al Gobierno el abuso de este procedimiento urgente ${ }^{78}$. Sin embargo, a diferencia de los " $\mathrm{Ca}$ -

75 Ibíd, págs. 906-907.

76 «El derecho encuentra ahí sin duda su merecido, pero no convendría que dichos artificios dañasen la coherencia de la política financiera del Gobierno, la cual se revela, normalmente, en la Ley de Presupuestos" [Vid. P. M. GaudemeT- J. Molinier, Finances Publiques (Budget/Trésor), vol. 1, 7. ${ }^{a}$ ed., Montchretien, París, 1996, págs 260-261].

77 Se trata, así, como irónicamente se ha definido, de "un agregado de disposiciones heterogéneas; en otros términos, un inventario jurídico del que no habría renegado el poeta Jacques Prévert" [M.C. Bergères, "Les cavaliers budgétaires", cit., págs. 1393-4].

78 M. J. Aglae, "Les cavaliers sociaux”, Revue de Droit Public, núm. 4, 2000, págs. 1164 y sigs. 
valiers budgétaires", en este caso la Corte Constitucional lo considera sólo un problema de inadmisibilidad, no de inconstitucionalidad y, por lo tanto, oponible sólo a las enmiendas parlamentarias previamente alegadas en sesión pública y no al proyecto presentado por el Gobierno ${ }^{79}$. En los últimos años, sin embargo se ha producido una inversión de la tendencia, en cuanto que esta llamada "théorie de l'entonnoir" (esto es, una limitación del derecho de enmienda, que exige una congruencia material con la disposición a la que se añade) que tuvo su origen con los "cavaliers budgétaires", a raíz de la DC 535, de 30 de marzo de 2006, se ha extendido también a los "cavaliers législatifs"

\section{EL PROBLEMA DE LAS LEYES ÓMNIBUS EN EL ORDENAMIENTO CONSTITUCIONAL ESPAÑOL}

Adelantaba ya al inicio de estas páginas como, desde un primer momento, la aparición de las leyes de acompañamiento había concitado la práctica unanimidad en la doctrina a la hora de exigir su inmediata desaparición con base en distintas consideraciones ${ }^{81}$. Ante todo, lo que subyace bajo la mayoría

79 Se ha destacado, en este sentido, la mayor flexibilidad demostrada por el Consejo Constitucional con las leyes de financiación de la Seguridad Social, cuyos "cavaliers sociaux" no son objeto de tanta rigurosidad en el control constitucional. L. PHILIP, "Nouvelles réflexions sur la nature et le devenir des lois de financement de la Securité Sociale", Droit Social, núms. 9/10, 1998, págs. 783-4. A favor de la necesidad de establecer criterios autónomos respecto de los establecidos para las leyes de presupuestos, vid. J. F. CALMETTE, "Les "cavaliers sociaux" dans la jurisprudence du Conseil Constitutionnel: une autonomie à petit trot", Revue Française de Droit Constitutionnel, núm. 61, 2005, pág. 171 y sigs.

80 R. Déchaux, "L'évolution de la jurisprudence constitutionnelle...", pág. 3.

81 Argumentos en los que, no obstante, no siempre existe la misma coincidencia, a lo que debe añadirse el hecho de que con excesiva frecuencia las críticas adolecen de la necesaria claridad, de manera que las distintas argumentaciones acaban por entremezclarse hasta perder parte de su consistencia. En cualquier caso, lo cierto es que no sólo la doctrina científica manifestó sus dudas respecto de la posible inconstitucionalidad de estas leyes. También desde numerosas instituciones públicas — tanto en el ámbito estatal como en el autonómico- se pusieron de manifiesto distintos reparos a las mismas. Básicamente, desde los principales órganos jurídico-consultivos, se advertía contra el uso y abuso de esta figura normativa, fundamentalmente debido a que «razones de seguridad jurídica y de buena técnica legislativa aconsejan que todas las normas, y muy en especial aquellas que tienen rango de Ley, nazcan en el seno propio de la materia que es objeto de regulación, y vivan dentro de ella hasta que sean sustituidas por otras" (Dictamen del Consejo de Estado de 3 de octubre de 1996, emitido con referencia al anteproyecto de la Ley de Acompañamiento aprobada ese año). También el Consejo Económico y Social (vid. su dictamen 3/1996, relativo al Anteproyecto de la Ley 13/1996) insistió en la denuncia de que la utilización extensiva de las llamadas Leyes de Acompañamiento presupuestario conlleva un riesgo de dispersión de la normativa, "restándole coherencia y dificultando su comprensión global, con el eventual riesgo, asimismo, de producir inseguridad jurídica en los intérpretes y aplicadores de las normas". Por su parte, el Consejo General del Poder Judicial, en su informe de 15 de octubre de 1997, referido al anteproyecto de Ley de Acompañamiento de la LPGE para 1998, advirtió de los riesgos de esta incorrecta técnica legislativa, especialmente respecto de los efectos derogatorios de estas leyes sobre la normativa existente. Por último, para acabar dando cuenta de la gravedad de la situación, es de destacar el hecho de que el propio 
de estas críticas es una común creencia de que las Leyes de Acompañamiento respetan las formas (la "letra", se dice) de la Constitución y de la doctrina del Tribunal, pero no así su "espíritu" ${ }^{82}$. Se ha afirmado, por ello, que "[l]a Ley de Acompañamiento sería en el fondo un trozo de la Ley de Presupuestos que se deja fuera — justo al lado — con la finalidad de sortear las limitaciones materiales de la susodicha Ley presupuestaria", por lo que "el juicio sobre las Leyes de Acompañamiento ha de tomar como referentes aquellas prescripciones constitucionales (e incluso aquellas configuraciones doctrinales del Tribunal Constitucional) sobre las Leyes de Presupuestos que puedan razonablemente afectarles". De este modo, al legislador se le reprochaba haber creado la categoría de las Leyes de Acompañamiento para dar cabida a todo aquello que el Tribunal Constitucional había excluido expresamente de las Leyes de Presupuestos. Se llegaba, así, a la acusación de "fraude de ley" tantas veces esgrimida contra las Leyes de Medidas Fiscales, Administrativas y del Orden Social, por considerarlas un mero expediente técnico ideado para sortear la limitación de contenido que pesa sobre las Leyes de Presupuestos, especialmente a raíz de la interpretación más rigurosa establecida por el Tribunal Constitucional ${ }^{84}$.

\section{a) Relación con las Leyes de Presupuestos Generales del Estado}

Llegamos entonces a aquellas teorías que llevan a cabo una extensión analógica de los límites constitucionales del art. 134 CE (que sólo habla de leyes de presupuestos), para acabar derivando, incluso, la clara inconstitucionalidad de las leyes acompañamiento por vulnerar los límites establecidos para las $\mathrm{LPGE}^{85}$. En efecto, aquellos autores que emplean la doctrina del

Ejecutivo, a través de un informe de la Secretaría General Técnica del Ministerio de Economía y Hacienda de marzo de 1999, apoyado en este amplio rechazo doctrinal e institucional hacia las Leyes de Acompañamiento, llegaba a la conclusión de que "la evolución del contenido de estas leyes ha llegado a un punto insostenible en cuanto al equilibrio del sistema jurídico, al cumplimiento del principio de seguridad jurídica y al ejercicio correcto de la función legislativa". Por este motivo, consideraba que "la gravedad de la situación determina la necesidad de encauzar estas leyes a su función originaria limitando su contenido al complemento necesario para la ejecución de la política económica del Gobierno".

82 Vid. L. M. Cazorla Prieto, Las llamadas Leyes de Acompañamiento..., cit., págs. 118 y sigs; R. Falcón Y Tella, "Ley de Presupuestos y leyes de "acompañamientom, en la presentación de Medidas Fiscales para 1997, Civitas, Madrid, 1997; M. A. MarTínez LaGo, Ley de Presupuestos y Constitución, cit., págs. 133 y sigs.; y V. M. SÁNCHEz BlázQuez, "Las Leyes de Presupuestos y las Leyes de Acompañamiento", RDFHP, núm. 242, 1996, pág. 881.

83 A. M. Cubero Truyo, "Las Leyes de Acompañamiento", cit., pág. 9.

84 S. Moreno González, Constitución y Leyes de "Acompañamiento" Presupuestario, Thomson-Aranzadi, Navarra, 2004, págs. 83 y sigs.

85 "[N]o se trata de una extensión directa y formal de las peculiaridades de la Ley de Presupuestos a la Ley de Acompañamiento, sosteniendo una identificación absoluta, sino de buscar cual es el sentido de esas peculiaridades para ver si éste proporciona claves constitucionales sobre el fenómeno que nos ocupa (escarbar en el contenido abstrayéndolo del continente)" [A. M. Cubero Truyo, "Las Leyes de Acompañamiento", cit., pág. 11]. 
fraude de ley —en la clásica formulación del profesor De Castro-, para concluir que las leyes de medidas constituyen un fraude a la doctrina del Tribunal Constitucional en materia de límites al contenido de las LPGE$^{86}$ se encuentran con la dificultad de identificar la ley defraudada o, en otras palabras, con el problema de realizar una aplicación extensiva del art. 134 CE (y de la correspondiente doctrina del Tribunal Constitucional en la materia) a las Leyes de Acompañamiento ${ }^{87}$.

En todo caso, parece que cuando se habla de las Leyes de Acompañamiento como mero instrumento fraudulento ideado in extremis por el legislador para sortear - al menos formalmente- los límites en el contenido admisible de las Leyes de Presupuestos, habrá que tener en cuenta, sobre todo, la fundamental restricción que sobre las LPGE impone el art. 134.7 CE al impedirles crear tributos (o modificarlos si no lo habilita previamente una ley tributaria). Al fin y al cabo es ésta la única limitación que la Constitución impone expresamente al contenido material de las Leyes de Presupuestos. De hecho, esta limitación al contenido de las LPGE es la única recogida de manera explícita por nuestra Norma Fundamental, a diferencia de otros textos constitucionales (significativamente, los artículos 81.3 de la Constitución italiana o 110.4 de la LFB), que impiden expresamente la regulación de otro tipo de materias mediante la Ley de Presupuestos. Sin embargo, de todos es sabido que, junto a los límites anteriormente señalados, el Tribunal Constitucional ha extraído del art. 134.2 CE (o, por mejor decir, de una lectura en negativo de este precepto) la existencia de unos llamados "límites implícitos" al contenido eventual de las $\mathrm{LPGE}^{88}$. En concreto, el Tribunal ha afirmado que los apartados 2 y 7 del art. 134 CE representan "dos círculos secantes que determinan el contenido de las distintas materias del ordenamiento jurídico que son susceptibles de inclusión en la parte dispositiva de la ley de presupuestos $", 89$. Con todo, el alcance y la propia existencia de esta limitación implícita del contenido de las Leyes de Presupuestos distan mucho de ser una cuestión pacíficamente admitida, y de lo controvertido de la cuestión es muestra clara

86 Según el maestro civilista, el fraude de ley consiste en "uno o varios actos que originan un resultado prohibido por una norma jurídica y que se ampara en otra norma dictada con distinta finalidad". De este modo, para que un acto pueda considerarse dictado en fraude de ley, deben concurrir dos requisitos: primero, que la validez de dicho acto suponga la vulneración de la ley defraudada; segundo, que la ley de cobertura (en la que el acto en cuestión se ampara), no ofrezca protección suficiente contra esta infracción. Vid. F. De Castro Y Bravo, Derecho Civil de España, Civitas, Madrid, 1984, pág. 544 y sigs.

87 Para un análisis detallado de las dificultades que presenta la identificación de la ley defraudada, véase A. JimÉNEz DíAz, "La impugnación de las Leyes Medidas...", cit., págs. 644 y sigs.

88 Los límites implícitos se han extraído de una lectura en negativo del art. 134.2 CE, allí donde dice que las LPGE "...incluirán la totalidad de los gastos e ingresos del sector público estatal, interpretado en combinación con el art. 66.2 de la propia Norma Fundamental. Un exhaustivo y crítico estudio de los mismos lo encontramos en J. A. TOSCANo OrTEga, Límites constitucionales al contenido material de las leyes de presupuestos del Estado, Congreso de los Diputados, Madrid, 2005.

89 G. De La PeÑa Velasco, "La delimitación del contenido constitucional de la parte dispositiva de las leyes de presupuestos en materia tributaria", REDF, núm. 99, 1998, pág. 400. 
el elevado número de ocasiones en que el Tribunal Constitucional ha debido enfrentarse al problema del contenido material de las LPGE, dentro de un contexto en el que ha intentado frenar la práctica habitual de los sucesivos gobiernos (con la consecuente connivencia parlamentaria) de incluir un sinfín de materias y disposiciones utilizando como vehículo las LPGE. A este respecto, es posible apreciar un cambio de enfoque en la doctrina del Tribunal, cuyo punto de inflexión lo encontramos en la ya mencionada STC 76/1992. De este modo, para nuestro Tribunal, a partir de dicho pronunciamiento, la Ley de Presupuestos es una ley en todos los sentidos, pero una ley especial, cuya singularidad deriva precisamente de la función que está constitucionalmente llamada a desempeñar. Por ello, continuando con el problema del que - en último término- derivan todas estas disquisiciones, esto es, la cuestión de la determinación del ámbito material de las LPGE, el Tribunal Constitucional ha admitido la presencia, junto a aquello que constituye su núcleo necesario (expresamente establecido en el art. 134.2 CE), sólo de aquellas otras materias que respeten dicha función constitucional de las LPGE, a partir de lo cual vendría constitucionalmente configurado lo que el Tribunal Constitucional ha denominado "contenido eventual" de las LPGE" ${ }^{90}$. Así, el Tribunal ha sostenido que las LPGE tienen un contenido "propio, mínimo y necesario", constituido, precisamente, por "la expresión cifrada de la previsión de ingresos y la habilitación de gastos" del sector público ${ }^{91}$. Pero, asimismo, junto a ese "contenido mínimo, necesario e indisponible ${ }^{92}$, admite la existencia de un "contenido posible, no necesario y eventual ${ }^{93}$ integrado por materias distintas a ese núcleo esencial, pero relacionadas con él.

Siguiendo esta doctrina del Tribunal Constitucional relativa al contenido material de las LPGE, desde ciertos sectores doctrinales se asegura que las Leyes de Acompañamiento —al igual que la Ley de Presupuestos- también desempeñan una función específica (aunque en este caso, obviamente, no se trataría de una función constitucionalmente determinada) que radicaría precisamente en su finalidad de servir de complemento de las Leyes de Presupuestos. De esta manera, para Cazorla Prieto la complementariedad de las Le-

90 Sin embargo, no es este el único criterio de delimitación del contenido material que el Tribunal Constitucional ha utilizado. Junto al respeto a la función constitucional (art. 134.2 CE), son otros dos los preceptos constitucionales considerados. De un lado, las especialidades de la tramitación parlamentaria (arts. 66.2 y 134.1, 6 y 7 CE), que implican ciertas limitaciones de las facultades parlamentarias de examen y enmienda. De otro, el principio de seguridad jurídica (art. $9.3 \mathrm{CE}$ ), según el cual una ley de contenido constitucionalmente definido no puede contener disposiciones distintas de aquéllas que le son propias de acuerdo a su función constitucional; una de cuyas manifestaciones principales sería la prohibición de introducir normas típicas del Derecho codificado.

91 STC 76/1992, FJ 4 a); en el mismo sentido, SSTC 65/1987, de 21 de mayo (FJ 4); 65/1990, de 5 de abril (FJ 4); 76/1992, de 14 de mayo, (FJ 4 a); 234/1999, de 16 de diciembre (FJ 4); 32/2000, de 3 de febrero (FJ 5); STC 109/2001, de 26 de abril (FJ 5); 67/2002, de 21 de marzo

(FJ 3); y 3/2003, de 16 de enero de 2003 (FJ 4).

92 STC 65/1987 (FJ 4).

93 STC 76/1992, FJ 4 a) 
yes de Acompañamiento respecto de las LPGE vendría expresada en tres distintas vertientes: política (provocada por la constante variabilidad de la realidad social), económica (inclusión de aquellas medidas no admisibles en el ámbito de las Leyes de Presupuestos) y jurídica (a partir de los límites sentados por la doctrina del Tribunal Constitucional en torno al art. 134.2 CE). A su vez, de la citada "función jurídica" desempeñada por las Leyes de Acompañamiento, dicho autor deduce la existencia de un requisito: el de la necesaria conexión de esta ley con el Presupuesto ${ }^{94}$. En esta misma línea, también Martínez Lago afirma la existencia de una "función jurídica" de las Leyes de Acompañamiento, consistente en la propia relación directa de complementariedad entre éstas y las Leyes de Presupuestos, de la cual deriva asimismo la necesaria limitación de contenido de las Leyes de Acompañamiento en cuestión ${ }^{95}$.

Lo cierto es, sin embargo, que el contenido de las Leyes de Acompañamiento siempre se caracterizó por ser tan absolutamente heterogéneo que abarcaba una universalidad de materias - fenómeno que, por otra parte, fue progresivamente en aumento. Así pues, tampoco existe una clara y precisa delimitación del objeto de estas leyes, ya que en su propio título (leyes de medidas fiscales, administrativas y de orden social), a priori, todo tendría cabida, de uno u otro modo. Por todo ello, resulta francamente problemático individuar esa función a la que se refieren los autores señalados. Considero, por el contrario, que a las Leyes de Acompañamiento no resultan de aplicación los límites constitucionales (y de los reglamentos de las Cámaras) que respecto de las Leyes de Presupuestos vienen establecidos. Ni creo que sea posible, tampoco, realizar una aplicación extensiva de la doctrina del Tribunal Constitucional sobre las Leyes de Presupuestos, porque sólo a éstas se refiere. Dice el Tribunal que la LPGE es un tipo de ley peculiar porque realiza una determinada función constitucional ${ }^{96}$, por lo que las limitaciones y restricciones que sobre ella recaen, sólo a ella serán aplicables. No creo, por tanto, en la posibilidad de extrapolar la doctrina constitucional, pues ésta se refiere a la Ley de Presupuestos y a ninguna otra. En este sentido, hay que partir de la premisa de que la libertad del legislador es total, dentro de los márgenes que le deli-

94 Conexión que, además, se produce en un triple ámbito: material, causal y final [L. M. CAzorla Prieto, Las llamadas Leyes de Acompañamiento..., cit., págs. 39 y sigs].

95 M. A. Martínez Lago, "Leyes de Presupuestos y leyes "de acompañamiento"...", cit., pág. 791. Esta misma argumentación —y casi empleando idénticos términos- fue desarrollada también en el anteriormente citado Informe de la Secretaría General Técnica del Ministerio de Economía y Hacienda de marzo de 1999, cuando hablaba de "la necesidad de encauzar estas leyes a su función originaria limitando su contenido al complemento necesario para la ejecución de la política económica del Gobierno" (cursiva nuestra).

96 Aunque en mi opinión (cuya pormenorizada explicación requeriría un mayor detenimiento y una complejidad que excede los modestos propósitos del presente trabajo), el art. 134.2 CE no establece la "función" que debe desempeñar la LPGE, sino que la Constitución le reserva el tratamiento de una materia concreta, es decir, establece una reserva de procedimiento por razón de materia. Para un mayor desarrollo de esta cuestión, vid. I. M. Giménez Sánchez, Las competencias presupuestarias del Parlamento, cit., págs. 242 y sigs. 
mita la Constitución, en el sentido de que - como resulta pacíficamente admitido- la relación que existe entre la ley y la Norma suprema no es cualitativamente equiparable a la establecida entre la Ley y el reglamento, por lo que en el caso que nos ocupa, dado que la Constitución no establece dichos límites, resulta inadmisible - por simple analogía - restringir la libertad del Parlamento en el ejercicio de su función legislativa.

Dicho lo cual, debe admitirse que en las Leyes de Acompañamiento concurren ciertas características que también a ella convierten en un tipo peculiar de ley. Características que deberán ser examinadas y valoradas con independencia de lo establecido respecto de las LPGE. En resumen, no se trataría tanto de efectuar un paralelismo con la Ley de Presupuestos, como de analizar autónomamente las Leyes de Acompañamiento, en cuanto leyes ordinarias, para comprobar si, en sí mismas consideradas, plantean algún tipo de inconstitucionalidad ${ }^{97}$. Es decir, si bien con la aprobación de las Leyes de Acompañamiento el Parlamento no está desempeñando esa función presupuestaria que se recoge en los arts. 66.2 y $134.1 \mathrm{CE}$, lo cierto es que sí deberá analizarse, en cualquier caso, si resultan o no de aplicación determinadas consideraciones manifestadas por el Tribunal Constitucional respecto de las exigencias del principio de seguridad jurídica y de respeto a las facultades de los parlamentarios, de donde puedan derivarse límites constitucionales al contenido de las Leyes de Acompañamiento (y cualesquiera otras leyes ómnibus), no ya con base en el art. 134, sino en los arts. 66.2 y $9.3 \mathrm{CE}^{98}$.

\section{B) El Respeto a las facultades Parlamentarias.}

La primera de las Leyes de Acompañamiento, esto es, la Ley 22/1993, se tramitó siguiendo el procedimiento legislativo de urgencia. Sin embargo, en las leyes sucesivas, esto no fue ya necesario, ya que se limitó a seguir la estela de las Leyes de Presupuestos". Esta "subordinación procedimental" de las Leyes de Acompañamiento dio lugar a su denominación como "leyes escolta" y es lo que, precisamente, suscitaba serias dudas acerca del respeto de las facultades de información, discusión y enmienda de los parlamentarios que deben aprobar estas leyes en un tiempo mínimo. Es por este motivo que todos los años, durante la tramitación parlamentaria de estas leyes, se sucedían invariablemente quejas y protestas de la oposición ante el apremio de los

97 V. M. SÁnchez Blázquez, "Las Leyes de Presupuestos ...", cit., pág. 880.

98 En sentido contrario, Cubero Truyo sostiene que no estamos ante "leyes específicas con problemas particulares, sino ante un método de intervención legislativa asentado", por lo que a la hora de valorar los preceptos en ellas contenidos "tales preceptos habrán de ser contemplados como manifestaciones de un proceder legislativo" ["Las Leyes de Acompañamiento", cit., pág. 10]

99 De hecho, es fácil comprobar como, pese a que el Gobierno presentaba ambos proyectos con una diferencia de aproximadamente una semana, al final se acababan discutiendo en el Parlamento con tan sólo uno o dos días de separación e, incluso, se aprobaban ambas leyes de manera simultánea. 
tiempos, lo apresurado de los debates, la imposibilidad de profundizar en ninguna de las diversas cuestiones que se presentaban a su aprobación e, incluso, la defectuosa información recibida por los parlamentarios individuales, que se veían incapaces de conocer seriamente el alcance de aquello que debían aprobar (muchas veces camuflado de manera estratégica en medio de ese totum revolutum). De este modo, cuando se lleva a cabo la comparación entre una ley ordinaria cualquiera y una Ley de Acompañamiento presupuestario, se "pone de manifiesto que la tramitación de esta última ha quedado totalmente envuelta o condicionada a la valoración y debate preeminente de la Ley de Presupuestos, de forma que se han producido de hecho todos los efectos y restricciones parlamentarias que constitucionalmente operan única y exclusivamente para las Leyes de Presupuestos, debido a su peculiaridad o especificidad ${ }^{100}$. Resulta por tanto innegable que, debido a la premura con que la aprobación de esta ley tiene lugar cada año y su oscurecimiento ante la innegable trascendencia de la contemporánea LPGE, se produce un más que deficiente desempeño de las funciones propias del procedimiento legislativo en el Parlamento. La información es insuficiente, no se debate rigurosamente..., en definitiva, no se cumple con las dos principales funciones atribuidas hoy a la potestad legislativa de las Cámaras, esto es, la de participación de las minorías y la de publicidad.

Esta restricción de las facultades parlamentarias juega en los dos sentidos, es decir, si por un lado la inclusión de un caótico aluvión de materias impide conocer con el rigor, la profundidad y el detenimiento debidos todas y cada una de las cuestiones incluidas en la Ley de Acompañamiento, por otra parte - y casi aún más grave- esta misma premura repercute de manera negativa en la preferencia de tramitación que la Ley de Presupuestos debería gozar respecto de cualquier otro asunto que puedan conocer las Cámaras. Pero eso no es todo. Las cosas se complican aún más si tomamos en consideración que existía la tendencia a acumular en el último trimestre del año el debate, tramitación y aprobación de todo tipo de leyes económicas ${ }^{101}$. De esta situación se derivan dos serios perjuicios para los parlamentarios (de modo especial, lógicamente, para aquellos de la oposición): primero, que los plazos de estudio y toma en consideración no sólo se acumulan, sino que frecuentemente se ven reducidos a la mitad, ex art. $91.2 \mathrm{RC}$; pero, además, al ser escasos los expertos en estas materias, acaban recayendo en un mismo parlamentario la la-

100 T. Olalde Martín, "Ley de Presupuestos versus Ley de Acompañamiento", cit., pág. 625.

101 Se lamentaba el profesor Ramallo Massanet (en su ya mencionada conferencia sobre "El bloque presupuestario en España: Presupuestos, Acompañamiento y Estabilidad") de como "parece desprenderse la existencia de una norma no escrita que consiste en que la legislación originada por los Ministerios de Economía y Hacienda se agolpa en los últimos tres meses del año lo cual provoca que las Comisiones parlamentarias legislativas afectadas (la de Economía, Comercio y Hacienda y la de Presupuestos) tengan una importantísima carga de trabajo". A modo de ejemplo, en esta categoría citaríamos la LO 7/2001, de 27 de diciembre, de modificación de la LOFCA; la Ley 22/2001, también de 27 de diciembre, de los FCI; más la Ley 21/2001 de acompañamiento al sistema de financiación de las Comunidades Autónomas (así como las de reforma del IRPF y Haciendas Locales...). 
bor de ser ponente en todas y cada una de las leyes que por esas fechas se discuten, lo que es obvio que redunda en detrimento de la calidad política y jurídica del debate del proyecto de ley".

Un último aspecto que vino a agravar dramáticamente los problemas suscitados en este punto por las leyes de acompañamiento, fue la práctica abusiva desarrollada en los últimos años de vida de este tipo legislativo, consistente en introducir numerosas enmiendas —algunas de ellas de gran trascendencia política y económica- durante la fase de discusión del proyecto legislativo en el Senado ${ }^{102}$. Un uso éste que concitó las más enérgicas críticas, y motivó algún recurso de inconstitucionalidad ante el Tribunal Constitucional, al considerarse una seria limitación de las competencias del Congreso - ya que estas modificaciones no permiten su debate posterior en la Cámara Baja, la cual debe limitarse a aprobarlas o, en su caso rechazarlas. De un somero análisis de las reformas introducidas por esta vía irregular en los últimos ejercicios, lo mínimo que puede decirse es que se ha tratado siempre de medidas heterogéneas, siempre planteadas de una manera inconexa y sin planificación $^{103}$. Frecuentemente la propia mayoría debía enmendar la en-

102 Con este motivo, denunciaba en su día el profesor Laporta dicha "utilización del Senado para evadir toda deliberación y legislar con urgencia a gusto del Gobierno. El Senado, por fin, parece haber encontrado esa misión que no aparecía clara en la Constitución: no es ya Cámara de segunda lectura, porque leer, lo que se dice leer, allí no se lee nada. Todo va en ella a tanta velocidad que no da tiempo para semejantes lujos. Pero es sin embargo indispensable como Cámara para una novedosa práctica: legislar de matute. Todo aquello que se quiere poner en vigor con prisas y poca reflexión va en una enmienda inesperada adherida a cualquier ley que esté tramitándose en el Senado. Eso es lo que se llama coloquialmente "colgar" enmiendas" ["La degradación de las Cortes Generales", El País, 5 de diciembre de 2003].

103 Así, cabe señalar como los proyectos de Ley de Presupuestos y de Acompañamiento para 2002 se vieron afectados por diversos bloques de enmiendas del Partido Popular en su paso por el Senado. Algunos de los polémicos aspectos modificados, fueron la enmienda del PP que excluía de las subvenciones electorales a grupos políticos integrados por personas que hubiesen sido condenadas por actos de terrorismo; o la implantación del nuevo impuesto sobre los carburantes para financiar la Sanidad, aprobado previamente por el Consejo de Política Fiscal. Pero quizás el punto más discutido y discutible fue el hecho de que, tras dos meses de debate presupuestario en el Congreso y en el Senado, el PP presentase in extremis una enmienda a la enmienda de otro grupo parlamentario, para introducir en la Ley de Acompañamiento del nuevo sistema de financiación autonómica una condición de aplicación que impedía que aquellas Comunidades Autónomas que no aceptasen el traspaso sanitario pudiesen disfrutar de las ventajas del nuevo sistema de financiación.

En la tramitación de los Presupuestos para 2003, la situación se repitió nuevamente: 170 enmiendas a la Ley de Acompañamiento presentadas in extremis en el trámite del Senado. En ellas, además de la lógica previsión de ayudas para los daños causados por el recientemente ocurrido desastre ecológico del hundimiento del buque Prestige, se modificaba un gran número de leyes (como la del deporte o de televisiones privadas). También asuntos de mayor entidad, como las nuevas tasas judiciales (que fueron objeto incluso de una enmienda a la enmienda, con el objeto de retrasar la entrada en vigor de la tasa al mes de abril, y lograr así un plazo de tiempo suficiente "para aprobar la orden de desarrollo de la ley y distribuir los modelos para abonar la tasa a todos los órganos jurisdiccionales afectados"); la previsión de un fondo de garantía de inversiones; o la bonificación en la contratación de víctimas de maltrato doméstico.

Finalmente, en el último ejercicio, la mayoría parlamentaria aprovechó el paso por el Senado de la Ley de Acompañamiento para introducir 179 enmiendas, que a su vez suponían la 
mienda, aún antes incluso de su discusión en la Comisión, en un intento de reparar sobre la marcha errores de bulto provocados por la premura y la precipitación en su introducción in extremis. En muchos casos se trató incluso de reformas trascendentes, de leyes varias, en materias relevantes que, desde un respeto del principio democrático y de la potestad legislativa de las Cámaras - pero también desde la propia exigencia de la calidad y coherencia del producto final, esto es, del Derecho positivo vigente - requerirían un debate parlamentario serio y riguroso. Una situación que se manifiesta de manera tanto más aguda cuanto más polémico y discutido es el contenido concreto de la reforma en sí, que hacen siempre sospechar de una cierta nocturnidad y alevosía por parte de quienes pretenden la aprobación de dichas medidas controvertidas sin respetar un ámbito suficiente de publicidad y discusión en sede parlamentaria. Y lo peor es que la mala costumbre no ha desaparecido ni siquiera a raíz de la supresión de las Leyes de acompañamiento, si bien es cierto que parece haber perdido ya su carácter patológico ${ }^{104}$.

\section{C) El RESPETO AL PRINCIPIO DE SEGURIDAD JURÍDiCA.}

Este problema ha sido planteado por la doctrina en dos planos distintos. De un lado, por parte de aquellos autores que - interpretando analógicamente la doctrina del Tribunal Constitucional respecto de la seguridad jurídica aplicada a las Leyes de Presupuestos - conectan la infracción del principio constitucional del art. 9.3 CE con la función específica de esta ley. De otra, quienes, única y simplemente analizando los contenidos habitualmente presentes en las Leyes de Acompañamiento —más allá de cualquier función que las mismas puedan desempeñar — valoran si dichos contenidos vulneran el citado principio constitucional.

Comenzando con la primera de las argumentaciones, el punto de partida no es otro que la propia doctrina del Tribunal, que podemos encontrar perfectamente expuesto en la STC174/1998, de 23 de julio (FJ 6º): "E]xigencia del principio de seguridad jurídica constitucionalmente garantizado (art. 9.3 CE) esto es, la certeza del Derecho que exige que una Ley de contenido constitucionalmente definido, como es la Ley de Presupuestos Generales, no contenga más disposiciones que las que corresponden a su función constitucional (arts. 66.2 y $134.2 \mathrm{CE}$ ), «debido a la incertidumbre que una regulación de este tipo origina" (SSTC 65/1990, 76/1992, 116/1994, 178/1994, 195/1994 у 61/1997)". A partir de esta premisa, pues, se defiende la necesidad racional de

modificación de una veintena de leyes. La mayor polémica se suscitó con una enmienda que suponía introducir un nuevo artículo 71 bis en la Ley de Tráfico, que facultaba a los agentes de la autoridad a proceder a la inmediata retirada permiso de conducción (enmienda que fue finalmente retirada).

104 El Gobierno socialista aprovechó la tramitación en el Senado de la LPGE para 2007 para introducir una importante reforma: la modificación de la Ley del Régimen del Personal del Cuerpo de la Guardia Civil de 1999 y añadir un nuevo rango en el escalafón del cuerpo. 
aplicar analógicamente la doctrina del Tribunal Constitucional acerca de las Leyes de Presupuestos, dada la función esencial desempeñada por ambas leyes. Sostienen así estos autores que - para respetar el principio de seguridad jurídica - las Leyes de Acompañamiento deben cumplir un triple requisito: relación directa, complemento necesario e inclusión justificada. De este modo, afirman, del principio de seguridad jurídica se derivaría directamente, como una exigencia constitucional, el requisito de que todas las materias contenidas guarden una relación de "complementariedad necesaria", bien con el núcleo mínimo necesario e indisponible de las Leyes de Presupuestos, bien con el contenido eventual de aquellas ${ }^{105}$.

No creo, sin embargo, que la cuestión de la inseguridad jurídica generada por este tipo de leyes esté relacionada con la hipotética función específica que estas leyes desempeñen. El principal problema que, a mi juicio, suscita esta construcción, es precisamente el de distinguir entre el contenido eventual de las Leyes de Presupuestos y ese contenido de complemento necesario a las mismas. En efecto, si las disposiciones a las que nos referimos deben guardar una relación directa con la materia presupuestaria, no se entiende el motivo por el que deban ser desligadas de la propia Ley de Presupuestos, ya que la propia jurisprudencia constitucional ha admitido su inclusión. Puesto que en nuestro ordenamiento jurídico no se plantea el problema de la naturaleza jurídica de las Leyes de Presupuestos y, por tanto, no ocurre como en otros sistemas de nuestro entorno, donde este tipo de leyes no pueden contener innovaciones del ordenamiento fuera de la necesaria autorización de gastos y previsión de ingresos, aquí, la cuestión, tal como lo ha planteado el propio Tribunal Constitucional, es más bien de respeto a los límites de la función presupuestaria que la Constitución atribuye a este tipo de leyes —las LPGE-. Por ello, el Tribunal ha admitido la inclusión en las Leyes de Presupuestos además del contenido mínimo y esencial - de aquellas otras materias cuya introducción "esté justificada, en el sentido de que sea un complemento necesario para la mayor inteligencia y para la más eficaz ejecución del Presupuesto y, en general, de la política económica del Gobierno" (STC 76/1992). De este modo, como puede comprobarse, el Tribunal incluso utiliza la misma expresión de "complemento necesario", que Cazorla Prieto establecía como requisito para la admisión de materias a regular por las Leyes de Acompañamiento, lo que nuevamente nos lleva a negar la tacha de inconstitucionalidad de las Leyes de Acompañaminto con base en la inseguridad jurídica relacionada con la presunta función específica atribuida a estas leyes.

Por el contrario, dentro del otro sector de la doctrina al que hacíamos mención al inicio de esta exposición, se hace hincapié en las características

105 Defiende Cazorla Prieto la necesariedad entendida en términos relativos, esto es, "que la normación presupuestaria a la que se refiere quedara imperfecta, de difícil o muy costosa integración, de complicada puesta en práctica, o que, sin ser imposible su vigencia, se convirtiera sin aquella en empeño plagado de escollos e imperfecciones" [Las llamadas Leyes de Acompañamiento..., cit., págs. 90 y sigs]. 
concretas de este tipo de leyes, desde su consideración de leyes ordinarias, sin ulteriores especialidades constitucionales ${ }^{106}$. En este sentido, la principal crítica reiteradamente vertida respecto de las Leyes de Acompañamiento es la de su más que deficiente técnica legislativa. En efecto, estas leyes vienen constituidas por un conglomerado inconexo de normas de origen dispar, procedentes de las más variopintas necesidades coyunturales de cada Ministerio. Son leyes sin ningún tipo de cohesión interna, que carecen de la menor estructura, constituyendo una sucesión de disposiciones sin conexión formal ni sustancial. Por ello, al hecho, ya de por sí altamente reprochable, de procederse a la modificación de un sinfín de disposiciones pertenecientes a su vez a diversas leyes vigentes, nos encontramos con que estas reformas se encuentran repartidas - de forma bastante aleatoria, todo sea dicho- entre la Ley de Presupuestos y la Ley de Acompañamiento. Además, para agravar en mayor medida este caos, es de destacar que ni siquiera dentro de la propia Ley de Acompañamiento se lleva a cabo una ordenación sistemática de las mismas, sino que, antes bien, dichas reformas aparecen desperdigadas a lo largo de los distintos capítulos, disposiciones adicionales, finales y transitorias, convirtiendo así en una "misión imposible" la labor de localización de la normativa vigente en cada una de las materias afectadas ${ }^{107}$. Por ello, no es extraño comprobar como un mismo impuesto (especialmente el IRPF) es modificado primero por la Ley de Presupuestos y más tarde por la Ley de Acompañamiento, tanto en su articulado como en varias disposiciones adicionales. Pero, además, cada una de las concretas disposiciones se caracteriza, a su vez, por poseer un contenido «técnico, sectorial, parcial y fragmentario" y emplear términos, expresiones y conceptos técnicos de difícil traducción jurídica y más difícil inteligibilidad ${ }^{108}$. Finalmente, destaca en estas leyes el hecho de que una gran parte de las disposiciones incluidas son normas que no reúnen las características de la generalidad y la abstracción — tradicionalmente atribuidas a las leyes - ya que, al regular supuestos muy concretos, y dado su alto grado de casuismo, serían más propias de las

106 Hemos ya señalado que para algunos sectores doctrinales la LPGE viene concebida como cualquier otra ley ordinaria, sin mayor limitación al contenido que la establecida en el apartado 7 del art. 134, y que por tanto sólo está impedida de crear nuevos tributos o modificar los ya existentes sin previa habilitación legal. Así pues, para dichos autores, tampoco constitucionalmente habría nada que objetar a los anteriores contenidos multiformes y larguísimos. [Vid. I. M. Giménez SÁnchez, Las competencias presupuestarias del Parlamento, cit., págs. 242 y sigs]

107 En esta misma línea, Cubero Truyo denuncia que el tratamiento de materias viene distribuido de manera aleatoria entre las distintas partes de la ley, sin que sea posible individuar ningún criterio que determine qué materias se incluyen en el articulado y cuáles en las disposiciones adicionales, ya que ni siquiera las modificaciones introducidas a través de disposiciones adicionales se presentan juntos. Finalmente - añade- "[a] todo ello hay que sumar el uso incorrecto o distorsionado de las cláusulas transitorias, derogatorias y finales". A modo de ejemplo, este autor recuerda el proceso modificador del impuesto de sociedades llevado a cabo por la LPGE y la Ley de Acompañamiento para 1995, que hacía imposible "una recopilación de los lugares — distintos, separados, insólitos - donde hay que buscar la regulación vigente del Impuesto sobre Sociedades" ["Las Leyes de Acompañamiento", cit., págs. 13 y 14].

108 L. M. Cazorla Prieto, Las llamadas Leyes de Acompañamiento..., cit., pág. 57. 
normas reglamentarias. En definitiva, esa inseguridad jurídica denunciada por la doctrina traería su causa precisamente de la «técnica legislativa de pésima calidad" que ha consagrado la práctica anual de las Leyes de Acompañamiento, precisamente por el hecho de incluirse en ellas "múltiples normas modificativas singulares de leyes formales, redactadas en la mayor parte de los casos con una desaconsejable premura que propicia la comisión de todo tipo de disparates" ${ }^{109}$.

Otro argumento esgrimido por la doctrina para censurar la vulneración del principio de seguridad jurídica por este tipo de leyes deriva del art. 134.7 CE. En efecto, la finalidad de dicho precepto se encuentra en la pretensión de estabilidad del ordenamiento tributario, al contemplar de una manera muy restrictiva la creación y modificación de tributos. Efectuando una lectura sensu contrario de dicho precepto constitucional, se ha afirmado que "[1]a estabilidad del Derecho no es sólo un presupuesto científico filosófico, sino que tiene una consagración constitucional, genérica en el principio de seguridad jurídica y específica para el ordenamiento tributario a través del art. 134.7„110. Por otra parte, si tenemos en cuenta la doctrina del Tribunal Constitucional para determinar el alcance del principio de seguridad jurídica ${ }^{111}$, hay que recordar ante todo que el Tribunal Constitucional ha venido conectado la confianza de los ciudadanos con el principio de seguridad jurídica, que es, así, según reiterada doctrina, "suma de certeza y legalidad, jerarquía y publicidad normativa, irretroactividad de lo no favorable e interdicción de la arbitrariedad, sin perjuicio del valor que por sí mismo tiene". Por ello, aun cuando dicho principio "no puede erigirse en valor absoluto, pues ello daría lugar a la congelación o petrificación del ordenamiento jurídico existente", el Tribunal ha reconocido que el mismo debe proteger "la confianza de los ciudadanos (...) frente a cambios normativos que no sean razonablemente previsibles " ${ }^{112}$. Sin embargo, en un sentido más estricto, la seguridad jurídica equivale a certeza en el Derecho, como así expresa el propio Tribunal en su Sentencia 46/1990, de 15 de marzo, "la exigencia del artículo 9.3, relativo al principio de seguridad jurídica implica que el legislador debe perseguir la claridad y no la confusión normativa, debe procurar que acerca de la materia sobre la que se legisle sepan los operadores jurídicos y los ciudadanos a qué atenerse, y debe huir de provocar situaciones objetivamente confusas".

109 J. A. Santamaría Pastor, "El sistema de fuentes del Derecho...", cit., pág. 557

110 A. M. Cubero Truyo, "Las Leyes de Acompañamiento", cit., pág. 12. El citado autor que hace suyas las críticas del Informe del Consejo de Estado de 1996, ya mencionado- basa su argumentación en el propio debate constituyente, que demostraría que el citado precepto "surgió como una "enmienda transaccional" que [...] vino a zanjar la controversia entre los partidarios de la flexibilidad del sistema tributario, basada en razones de política económica general [...] y aquéllos que defendían el principio de "buena ordenación de la Hacienda"m.

111 Para un análisis de la jurisprudencia constitucional, especialmente aplicado a la materia financiera, reenviamos a C. GARCíA NovOA, El principio de seguridad jurídica en materia tributaria, Marcial Pons, Madrid, 2000.

112 SSTC 126/1987, de 16 de julio; 197/1992, de 19 de noviembre; 173/1996, de 31 de octubre; y 182/1997, de 28 de octubre. 
Así, con apoyo en la transcrita doctrina constitucional, es posible afirmar que, ciertamente, una deficiente técnica legislativa no equivale en sí misma considerada a una vulneración del principio de seguridad jurídica, pero sí puede operar como un elemento agravante cuando otros se añaden ${ }^{113}$. A esto cabría añadir, en numerosos casos, la falta de claridad de las normas contenidas en las Leyes de Acompañamiento, debido a su heterogénea procedencia, a la falta de un debate con detenimiento en el Parlamento y a su excesivo tecnicismo, circunstancias todas ellas que se alían negativamente para dar lugar a normas incomprensibles para el ciudadano ${ }^{114}$. Finalmente, hay que hacer hincapié en que se ha demostrado que el problema no afecta sólo al ciudadano de a pie, sino que los propios aplicadores del Derecho se ven sumidos en una enorme confusión normativa, debido al enorme número de normas que anualmente se ven reformadas o incluso derogadas con la aprobación de la Ley de Acompañamiento y otras "leyes escoba" equivalentes ${ }^{115}$.

En nuestra opinión, las Leyes de Acompañamiento (o, en sí, cualquier otra ley ómnibus) adolecen de unos vicios o defectos de técnica legislativa que, aun no considerándolos causa de inconstitucionalidad, no son todo lo respetuosos que debieran con el principio constitucional de seguridad jurídica proclamado en el artículo $9.3 \mathrm{CE}^{116}$. Es más, este tipo de leyes bien podrían ser calificadas, sin temor a excedernos, como instrumentos de fomento de la inseguridad jurídica ya que dificultan, no sólo a los ciudadanos sino también a los operadores jurídicos que han de interpretar y aplicar las normas, el conocimiento del Derecho vigente y aplicable ${ }^{117}$, recordando la comparación que establecía el profesor Tomás y Valiente, de estas leyes con el "edictum traslaticium como acceso al edictum perpetuum ${ }^{118}$. No se trata, por tanto, de vulneraciones de hipotéticas funciones constitucionales específicas — de un

113 Vid. STC 76/1990 (FJ 8), donde el Tribunal admite que, aun cuando la técnica jurídica no constituye, per se, una exigencia del principio de seguridad jurídica, sí desempeña un importante papel.

114 "Los principios de seguridad jurídica e interdicción de la arbitrariedad de los poderes públicos exigen que la norma sea clara para que los ciudadanos sepan a qué atenerse ante las mismas" (STC 150/1990, FJ 8).

115 Cazorla Prieto recoge el ejemplo del caos normativo provocado en 1996, cuando se dieron lugar distintas leyes de contenido variado, provocando una situación de indudable inseguridad jurídica; hasta el punto de que, respondiendo a las exigencias de jueces y tribunales, en octubre de ese mismo año, el CGPJ se vio obligado a encargar un texto refundido con todas las leyes afectadas y poder conocer así cuál era efectivamente el Derecho vigente [Las llamadas Leyes de Acompañamiento presupuestario..., cit., pág. 103]

116 STC 150/1990 (FJ 8): "...no cabe subestimar la importancia que para la certeza del Derecho y la seguridad jurídica tiene el empleo de una depurada técnica jurídica en el proceso de elaboración de las normas (...); puesto que una legislación confusa, oscura e incompleta, dificulta su aplicación y, además de socavar la certeza del Derecho y la confianza de los ciudadanos en el mismo, puede terminar por empañar el valor de la justicia".

117 F. X. Sambola Cabrer, "Leyes de presupuestos, "Leyes de Acompañamiento" y seguridad jurídica", http://noticias.juridicas.com, Abril 2000, in fine.

118 Vid. sus Obras Completas, vol. III, Centro de Estudios Políticos y Constitucionales, Madrid, 1997, pág. 1999 
tipo legislativo absolutamente novedoso que, en consecuencia, la Constitución ni siquiera previó. El problema auténtico viene dado por el hecho de que una ley - tramitada además mediante el procedimiento legislativo de urgenciatrate de una enorme cantidad de materias absolutamente dispares, carentes de conexión alguna entre ellas. En estas condiciones, "[n]i los parlamentarios pueden, con un mínimo de racionalidad y coherencia, discutir mil materias diferentes al mismo tiempo, ni los ciudadanos pueden entender fácilmente una ley en la que se mezclan innumerables fragmentos, y sólo fragmentos, de la regulación de las materias más diversas" ${ }^{119}$. Pero, entiéndase bien, esta vulneración del principio de seguridad jurídica no viene dada por el hecho de que se trate de la LPGE, o de la Ley de acompañamiento y como tal un fraude a la jurisprudencia constitucional respecto del contenido posible de las LPGE, sino que es una inconstitucionalidad propia de las llamadas leyes ómnibus o leyes de objeto diverso ${ }^{120}$.

\section{CONCLUSIONES Y ALTERNATIVAS POSIBLES}

Parece que cualquier tipo de norma restrictiva del contenido de las Leyes de Presupuestos acaba condenada a chocar contra la realidad de los hechos. La prueba la encontramos en nuestra propia historia y en el Derecho comparado. Bien sea mediante la vulneración abierta y explícita de esta restricción del contenido admisible de las Leyes de Presupuestos, bien acudiendo a expedientes más tortuosos (normalmente la creación de una ley paralela que acaba por atraer en sí todo lo que a la Ley de Presupuestos no le está permitido) se diría que resulta prácticamente inevitable acabar cayendo en la tentación de acudir a un vehículo normativo de capacidad casi ilimitada. Lo cual debe hacernos reflexionar que "la persistencia del fenómeno [...] obedece a alguna razón suficiente para que el cumplimiento de las normas limitadoras sea tan escasamente significativo [...], ya que su producción, constante y repetida, no puede obedecer solamente a razones y motivos coyunturales" ${ }^{121}$. De hecho, algún autor ha sostenido que la Ley de Acompañamiento es la ley que refleja en mayor medida - más aún si cabe que la propia Ley de Presupuestos- su calidad de "norma esencial de dirección política gubernamental de cariz global" ${ }^{122}$.

119 J. J. FERREIRo LAPATZA, "Derecho Presupuestario y técnica legislativa", $R E D F$, núm. 87, julio-septiembre 1995, pág. 492. Este párrafo —dedicado a las LPGE — resulta, sin embargo, de aplicación en todos sus extremos a las Leyes de Acompañamiento y, en general, a cualquier otra "ley ómnibus".

120 De hecho, en Francia, existe junto a las figuras de los "cavalier budgétaire" y "cavalier social", la del "cavalier législatif".

121 Debido fundamentalmente a motivos relacionados con razones de agilidad y urgencia, a su vez ligadas a la propia naturaleza cambiante de la política económica [V. Querol BeLlido, "Modificaciones legislativas mediante el articulado de las leyes anuales de Presupuestos del Estado", Presupuesto y Gasto Público, núm. 23, 1985, pág. 105].

122 L. Jimena Quesada, Dirección política del Gobierno y técnica legislativa, cit., pág. 213 (cursivas en el original). 
En cuanto a la aplicabilidad de los límites que el Tribunal Constitucional ha configurado respecto de la LPGE, trasponiéndolos al caso de las Leyes de Acompañamiento, querríamos cerrar con unas breves consideraciones:

En primer lugar, partiendo de la premisa de que ni en la Constitución ni en el bloque de la constitucionalidad se contiene ninguna mención a este tipo de leyes, resulta imposible extraer la existencia de una función constitucional predicable de las mismas. Puesto que se trata de una ley ordinaria, al límite se podrá decir que «su finalidad no es otra que la que determine su contenido, orientado, como hemos visto, a "coadyuvar al cabal cumplimiento" o "mejorar la ejecución de los objetivos económicos previstos en la Ley de Presupuestos", mediante la adopción de medidas cuyo denominador común se halla en constituir instrumentos eficaces al servicio de la acción política del Gobierno" ${ }^{123}$.

Asimismo, al tratarse de una ley ordinaria, su procedimiento de tramitación será el procedimiento legislativo común. Nuevamente aquí debemos hacer mención sin embargo, al problema de los tiempos y los plazos. En efecto, si uno de los motivos principales (si no el de mayor peso) que -tradicionalmente y en la generalidad de los sistemas - se ha alegado para limitar la inclusión de materias extrapresupuestarias en las Leyes de Presupuestos ha sido la de la restricción de sus plazos, es obvio que este problema se verá agravado con la introducción de esta nueva ley que debe tramitarse de forma paralela (ya que, como su propia denominación indica, "acompaña" a la LPGE durante todo su iter parlamentario). Esta limitación del tiempo funciona, pues, en un doble sentido: por un lado, impide tratar la Ley de Presupuestos con el detenimiento debido a una ley de su trascendencia política y económica y, por otro, obliga a que una enorme cantidad de materias (y, por añadidura, absolutamente dispares) deban ser tramitadas mediante el procedimiento de urgencia, lo cual, sin duda, va en detrimento de las facultades de enmienda y de discusión de los parlamentarios.

Finalmente, relativo al respeto al principio de seguridad jurídica, es éste el punto donde mayores y más justificadas críticas pueden oponerse a estas leyes: acumulación de materias reguladas, disparidad e inconexión entre las mismas, frecuentes reformas de todos los sectores del ordenamiento. Es, así pues, respecto de esta cuestión donde se plantea en toda su extensión el problema de los límites entre la inadecuada técnica jurídica y la infracción del principio constitucional de la seguridad jurídica.

Respecto de las soluciones planteadas para hacer frente a esta situación, una más de las iniciativas a considerar -ya enunciada cuando se analizaba el problema que nos ocupa en el sistema estadounidense- era la propuesta de las leyes de objeto único ${ }^{124}$. En esta misma línea reivindicada por la doctrina

123 L. González Del Campo, "Nuevos problemas en torno al ejercicio de la potestad presupuestaria por el Parlamento", en Parlamento y justicia constitucional (IV Jornadas de la Asociación española de Letrados de Parlamentos), Aranzadi, Madrid, 1997, pág. 591.

124 Una exigencia que trae sus orígenes desde el Derecho romano cuando se aprobó la Lex Caecilia Didia en el año 98 d.C., que prohibía la práctica del fenómeno conocido como lex sa- 
norteamericana, habría que señalar las medidas introducidas con la reciente Ley 1/1998, de 26 de febrero, de Derechos y Garantías de los Contribuyentes. Fundamentalmente cabe destacar la inclusión de dos artículos que afectarían al tema al que nos referimos: de una parte, el art. 4 de la Ley 1/1998 dispone que "las leyes y los reglamentos que contengan normas tributarias deberán mencionarlo expresamente en su título y en la rúbrica de los artículos correspondientes; y que las leyes y los reglamentos que modifiquen normas tributarias contendrán una relación completa de las normas derogadas y la nueva redacción de las que resulten modificadas" ${ }^{125}$. Ciertamente, mediante esta Ley "no se afrontan los problemas que causan la inseguridad, sino sus consecuencias” ${ }^{126}$, pero quizá sea bueno que el legislador comience a ser consciente de los perniciosos efectos que sobre la seguridad jurídica tiene este modo caótico de legislar. Ya desde hace tiempo se viene reclamando una reforma del ordenamiento tributario realizada de forma sistemática, siguiendo una determinada filosofía; en vez de la actual tendencia, consistente en sistemáticamente reformar el orden tributario un par de veces al año ${ }^{127}$. Y, ciertamente, desde el punto de vista del respeto al principio de seguridad jurídica, nada peor que ese reparto aleatorio de reformas entre ambas leyes - la de Presupuestos y la "acompañante» - sin el menor criterio sistematizador en la redacción de las normas, de modo que todas estas innovaciones referentes a varias decenas de leyes ya en vigor aparecen dispersas aleatoriamente entre dos distintas leyes, carentes de la más elemental sistematización u ordenación lógica.

En definitiva, considero que la solución pasa en una gran medida por la propia concienciación del Parlamento, tras esta dejación de sus deberes ins-

tura, esto es leyes de materias heterogéneas e inconexas [Vid. J. P. ScHuck, "Returning the one to Ohio's one-subject rule", cit., págs. 899-900].

125 Por otra parte, el art. 6 de la misma ley obliga al Ministerio de Hacienda a publicar en el primer trimestre de cada ejercicio: a) los textos actualizados de aquellas leyes y reglamentos que hayan sido modificados durante dicho ejercicio; b) una relación de todas las disposiciones tributarias aprobadas en el mismo intervalo. El objeto de estas disposiciones, según se establece en el art. 13 de la Memoria adjunta a dicha Ley, es el de "facilitar el conocimiento, por los contribuyentes, de las normas tributarias, como medida que coadyuve al cumplimiento voluntario de las mismas". Sin embargo, se ha señalado acertadamente que éstas no dejan de ser normas de carácter eminentemente programático, dado que ninguna sanción se prevé frente a su incumplimiento [Cfr. F. Alonso Murillo (et alt.), Comentarios a la Ley de Derechos y Garantías de los Contribuyentes, McGraw Hill, Madrid, 1998, pág. 29]. Una muestra de la escasa confianza en el cumplimiento de estas previsiones lo constituye el hecho de que ya el art. 16 de la antigua Ley General Tributaria contenía la obligación de recoger todas las normas derogadas y la nueva redacción de las modificadas. De su nulo cumplimiento da fe la necesidad de reiterarlo en esta Ley de 1998.

126 Ibídem, pág, 49.

127 En este mismo sentido, Delgado González señalaba la gravedad del problema anterior cuando a éste se añade el enorme retraso en el conocimiento de los asuntos en materia tributaria ("casi tres años por término medio (...) tarda en resolverse un recurso contencioso-administrativo ante el Tribunal Superior de Justicia de Madrid", plazo al que, además, habrá de añadirse el de la necesaria vía económico-administrativa previa). Todo ello conlleva que numerosos fallos sean dictados aplicando normas derogadas mucho tiempo atrás ["La reforma de la justicia y el orden tributario", El País, Sábado 18 de mayo de 2002]. 
titucionales que ya desde hace tiempo ha venido haciendo gala. La práctica de las Leyes de Acompañamiento y la utilización abusiva y sistemática de las leyes de objeto diverso (especialmente en materia económico-financiera) resulta en cualquier caso altamente reprochable desde un punto de vista de técnica jurídica y, en consecuencia, recomendable tanto al Gobierno como a las Cámaras un ejercicio de auto-restricción para acabar con esta práctica. Por ello, resulta necesario insistir en que lo importante no es que la ley sea la LPGE, o la de Acompañamiento, sino intentar poner freno en el futuro a este tipo de iniciativas consistentes en aprobar macroleyes convertidas en auténticos cajones de sastre, en las que frecuentemente se limitan a responder a las demandas de los distintos socios políticos, o de los lobbies económicos sin permitir un adecuado debate parlamentario ${ }^{128}$. Por último, como medida extrema para impedir la proliferación de estas enmiendas, quizás cabría proponer que las Mesas del Congreso y el Senado se negaran a calificar iniciativas ajenas al objeto del texto discutido, reforzándose la exigencia de congruencia entre las enmiendas parlamentarias y el objeto sobre el que verse el proyecto o proposición de ley al que aquéllas se refieran: en otras palabras, importar la doctrina francesa de los "cavaliers" ${ }^{129}$.

ABSTRACT.- This article deals with the problem of the "Omnibus legislation", which is especially questionable when it comes to the budget law. In Spain this situation was represented by the figure of the so-called "Leyes de Acompañamiento presupuestario", now disappeared from the State level, but not from the regional one. In any case, this is not an exclusive problem of Spain, but we can also find the same (or too similar) practice in most of the constitutional systems. The technique of appending substantive provisions to appropriations bills has become a favorite tool of the legislative trade in recent years. Parliaments have employed "appropriations riders" to dictate the outcome of public policy issues, allowing significant changes in policy to be made without public input or legislative accountability. The policy changes implemented through the appropriations process would likely not survive the scrutiny of specialized committees and full floor debate.

128 "La técnica de las Leyes de Acompañamiento equivale en la práctica a consagrar una potestad legislativa efectiva y fulminante a todos los despachos administrativos, sin que las Asambleas Legislativas dejen de ser apenas meros lugares de registro. La democracia parlamentaria queda puesta en cuestión". E. GARCía De ENTERRía, Justicia y seguridad jurídica en un mundo de leyes desbocadas, Cuadernos Civitas, Madrid, 2000, pág. 89.

129 En este sentido, A. Díaz-Romeral Gómez, "De nuevo sobre el derecho de enmienda y sus límites. La congruencia entre la enmienda y el objeto del proyecto o proposición de ley a que se refiere y su deseable proyección sobre las leyes de acompañamiento", Cuadernos de Derecho Público, núm. 15, 2002, págs. 114 y sigs. En un sentido más amplio, vid. P. García-Escudero MárQUEZ, El procedimiento legislativo ordinario, CEPC, Madrid, 2006, págs. 260-262 y la bibliografía citada en la n. 426. 